\title{
أثرتوظيف التعلم القائم على المشروع في القدرة الرياضية لدى طالبات الصف التاسع الأسـاسي في الأردن
}

\section{الاء أحمد الزعتري}

طالبة دكتوراة في مناهج الرياضيات وأساليب تدريسها- قسم المناهج وطرق التدريس- كلية التربية- جامعة اليرموك- الأردن Alaa2014403122@gmail.com

\section{أمل عبدالله خصاونة}

أستاذ في مناهج الرياضيات وأساليب تدريسها- كلية التربية- جامعة اليرموك- الأردن

amal.khasawneh@yu.edu.jo

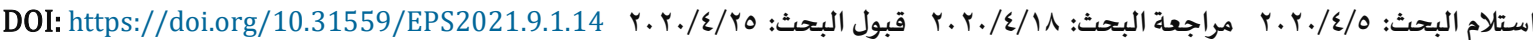

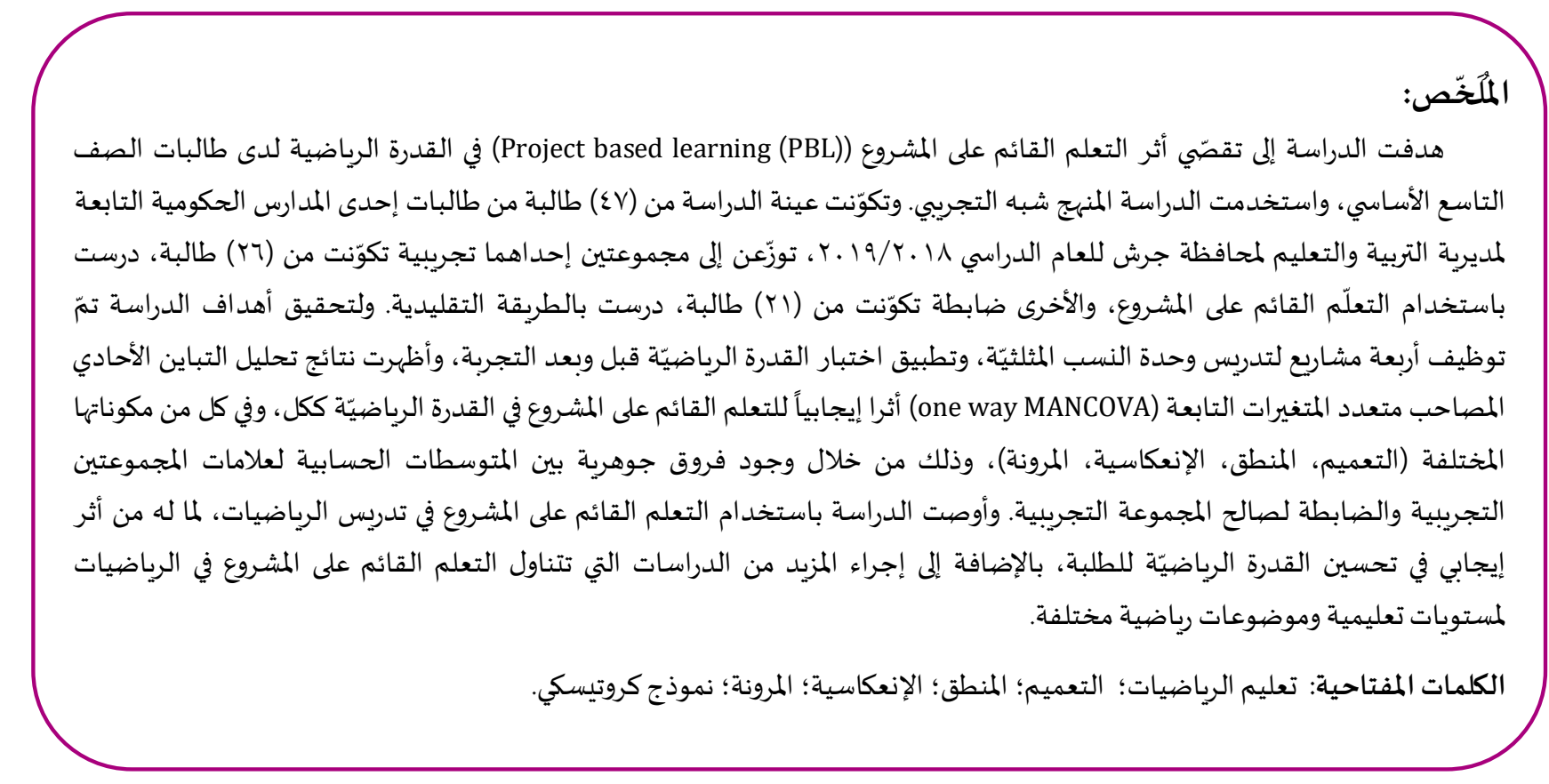

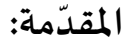

تلعب الرياضيات دوراً محورياً في تقدم الحضارة الإنسانية، وتُعدّ في مقدمة العلوم التي يمكن من خلالها تطوير تفكير الطلبة ومهاراتهم، علاوة على لئل

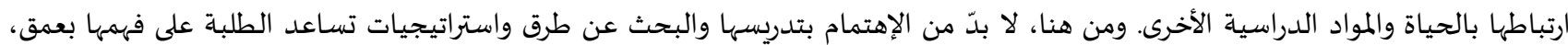

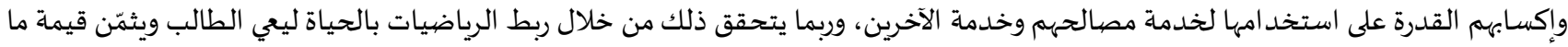

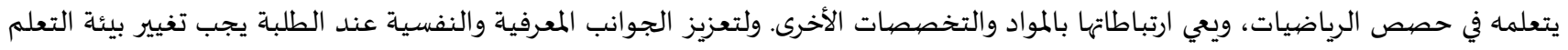

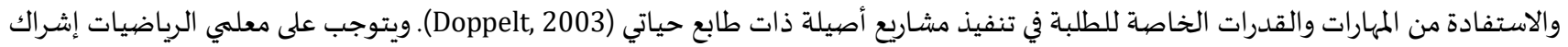

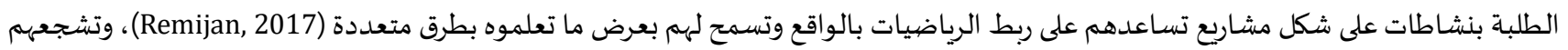
على عمل استقصاءات ذاتية عميقة لمشكلات من الحياة الواقعية ذات صلة ومعنى بحياتهم اليومية (Bell, 2010)، وتمكنهم من تطوير معرفة عميقة بالمحتوى بالإضافة إلى مهارات التعاون والإبداع والتواصل (Buck Institute for Education, 2018; Bender, 2012). 
ويحدّد نول (Knoll, 2014) ملامح هذه المشاريع بأنها نشاطات عملية يشارك فيها الطلبة لحل مشكلة معقّدة، خلال فترة معينة من الزمن، بشكل فردي أوجماعي. أمّا التعلم القائم على المشروع، فقد عرّفه بل (Bell, 2010) بأنّه طريقة تدريس محورها الطالب، بحيث تكامل بين المعرفة الخاصية

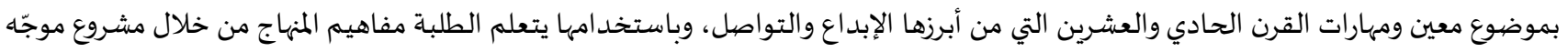
بسؤال استقصائي يسمح لهم بتطبيق المعرفة المكتسبة. ويكون المشروع هو أساس التعلم في الوحدة الدراسية وليس نشاطاً إضافياً أو تكميلياً لدعم

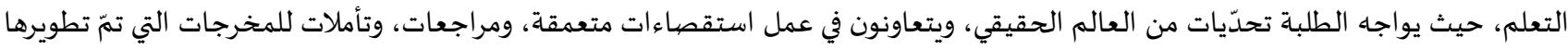

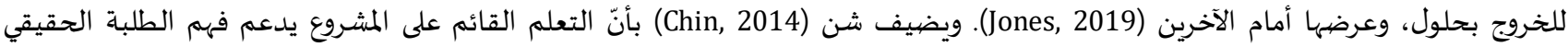

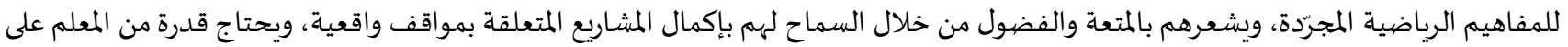

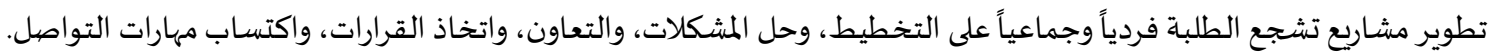
وبالنسبة لجذور التعلم القائم على المشروع، فقد أسّس لها العديد من التربويين التقدميين وعلماء النفس المعرفيّيّين أمثال ديوي وبياجياء وفيجوتيسكي، ووضعوا الأسس النفسية والمنهجية للتعلم القائم على المشروع، فقد لاحظ ديوي أنه يجب توجياء الأطفال وتزويدهم بخبرات التعلم

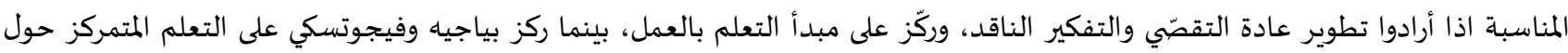

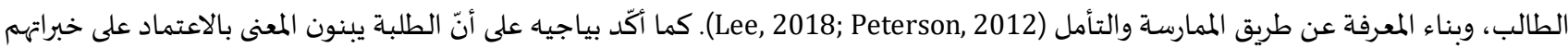

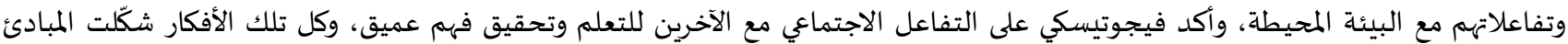

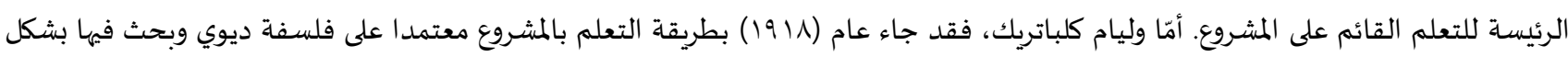

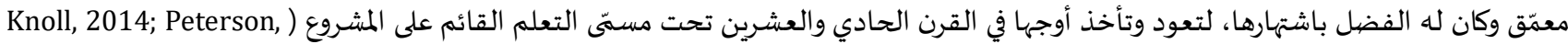

وتتلخص مراحل أوخطوات النشاط الحقيقي للتعلم القائم على المشروع كما أوردها لي (Lee, 2018) بتقديم المشروع للطلبة من خلال سؤال

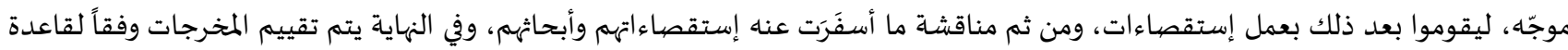

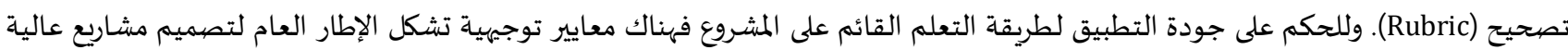

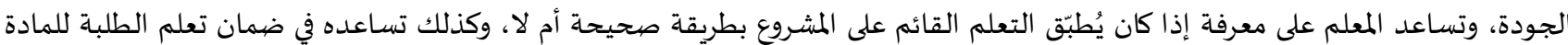
الدراسية والمشاركة في تعلم قائم على المشروع عالي الجودة. وقد حدّد ثوماس (Thomas, 2000) تلك المعايير بالآتي: المركزية (Centrality): تشير إلى ضرورة أن يتعلم الطلبة المفاهيم الرئيسة من خلال المشروع وأن لا تكون المشـاريع لإثراء أوتطبيق التعلم السابق. السؤال الموجه (Driving question): تركيز المشاريع على المشكلات والتحديات التي تقود الطلبة وتدفعهم المى مواجهة المفاهيم والمبادئ الأساسية في المادة العلمية موضع الاهتمام في عمليتي التعليم والتعلم. الواقعية (Realism): تمحور المشروع حول مشكلة حياتية واقعية.

الاستقصاءات البنائية (Constructive investigations): ضرورة أن تتضمن المشاريع إجراء استقصاءات تقود الطلبة إلى بناء معارف جديدة. •القيادة الذاتية (Autonomy): أن يتولى الطلبة قيادة المشروع بينما يأخذ المعلم دور الموجّه. ولا شك أنّ استخدام التعلم القائم على المشروع ينطوي على فوائد عدة منها تحسين الدافعية وزيادة التحصيل (هزهوزي، 17 ـــ)، وتحسين الإتجاهات نحو الرياضيات (Koparan \& Guven, 2014). ويشير يو وماهر (Yoo \& Maher, 2017) إلى أن الطلبة يطوّرون مهارات التعلم الذاتي

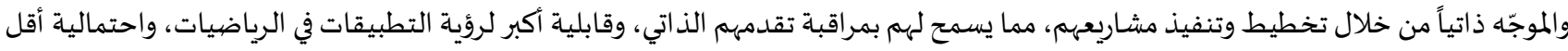
لرؤية الرياضيات كمهارات منفصلة. كما ينمّي التعلم القائم على المشروع مهارات التواصل، ويعطي رؤية واضحة للمعلمين حول عادات وأنماط التعلم

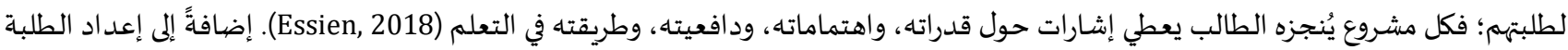
لمواجهة تحديات المستقبل، من خلال إكسابهم المهارات الضرورية لذلك (Bender, 2012). ويعدّ هذا هدفًا أساسيًّا لطرق التدريس الحديثة، ويمكن

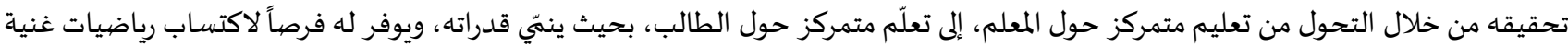
بالعمق والفهم، وامتلاك قدرات رياضية وليس فقط معرفة رياضية؛؛ قدرات تمكّنها من التعامل مع المشكلات الرياضية والحياتية.

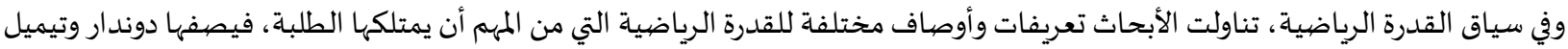
وجوندز (Dündar, Temel \& Gündüz, 2016) بأنها مركّب من خمسـة عناصر وهي: المهارات السببية (تطوير الفرضيات، التبرير الاحصائي والاحتمالي،

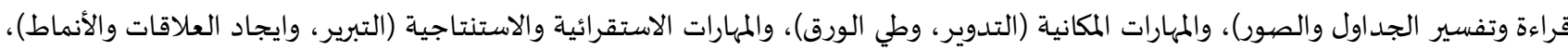

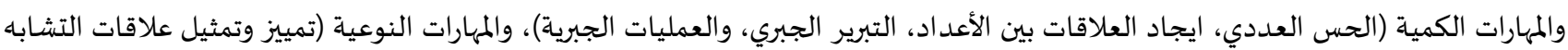
والاختلاف). ويرى متيلسكي (Metelski) المشار الياه في ميهاجلوفيك واجيريك وديجيك (Mihajlović, Egerić, \& Dejić, 2008) أن الأوصاف التي تناولتها 
أبحاث القدرة الرياضية تدور حول القدرة على التجريد، والقدرة المكانية أو الحس الهندسي، والحدس الرياضي، والمرونة، والقدرة المنطقية، والقدرة

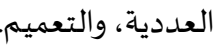

ويُعدّ "نموذج كروتيسكي" رغم كل الدراسات التي أتت بعده لتحديد القدرة الرياضية هو الأهم والأجدر بالثقة (Szabo, 2017)، حيث يعطي صورة واضحة عن طبيعة القدرة الرياضية، لذلك يمكن اعتباره بمثابة أساس لتحديد الطلبة ذوي القدرات الرياضية، لأنه يحدد معايير دقيقة لذلك (Vilkomir \& O’Donoghue, 2009) فقد قدّم كروتيسكي الخطوط العربضة لبنية القدرة الرياضية نتيجة إثنتي عشرة سنة من دراسة قدرات ( . . (Y) طالب من الأطفال في الرياضيات المدرسية، ليثبت أنّ القدرة الرياضية يمكن أن تتطور بصورة تدريجية مع مرور الوقت نتيجة للمرور بالخبرات

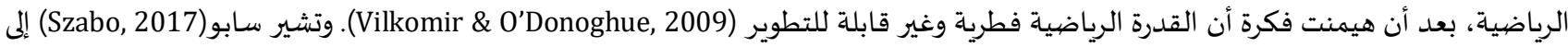

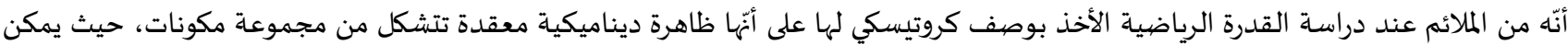
تطوير كل مكون من خلال الأنشطة المناسبة. ويشير كروتيسكي (Krutetskii, 1976) إلى وجود ثلاثة مراحل أساسية للنشاط العقلي عند حل أي مشكلة رياضية وهي جمع المعلومات اللازمة لحل المشكلة؛ أي فهم جوهر المشكلة، ومعالجة المعلومات من أجل الوصول إلى حل، والاحتفاظ بالمعلومات حول الحل، ومن هنا خلص إلى أنّ بنية القدرة الرياضية لدى الطالب هي مركّب من هذه القدرات:

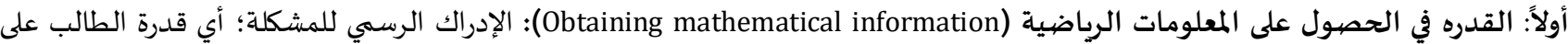

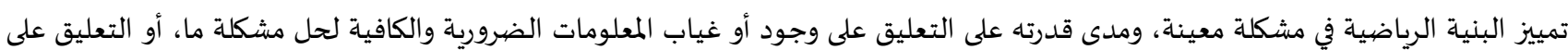
المعلومات الزائدة المعطاة في تلك المشكلة. ثانياً: القدره على معالجة المعلومات الرياضية (Processing mathematical information): تنطوي القدرة على معالجة المعلومات الرياضية على عدد من القدرات بما في ذلك: المنطق (Logic): القدرة على التوصل لنتيجة كإجابة لمشكلة رياضية ما من خلال عمل سلسلة من الاستنتاجات والمحاكمات بناءً على المعلومات المقدّمة في المشكلة. التعميم (Generalization): يتمثل بمستويين، القدرة على إدراج حالة خاصة ضمن مفهوم عام معروف؛ أي قدرة الطالب على تطبيق صيغة يعرفها مسبقاً على حالة خاصة، والاستنتاج العام من حالات خاصة لتشكيل مفهوم؛ أي قدرة الطالب على استنتاج صيغة غير معروفة له على أساس حالات خاصة.

التقليص (Curtailment): اختصار العمليات الرياضية التي يمكن استدعاؤها وشرحها من قبل الطلبة أثناء حل المشكلة. المرونة (Flexibility): مرونة العمليات العقلية في النشاط الرياضي، وتتمثل في تنوع الطرق التي تؤدي الى الحل والتي تعكس بدورها أفكاراً وتصورات مختلفة حول الفكرة الرياضية.

أناقة الحل (Elegance of Solution): السعي من أجل الوضوح والبساطة والاقتصاد للحلول. الإنعكاسية (Reversibility): تشكّل الإنعكاسية نوعا من شبكات الربط المعرفية، وتتمثّل بقدرة الطالب على التحوّل من الإتجاه المباشر للعملية العقلية إلى الإتجاه المعاكس؛ كأن ينتقل الطالب من النتيجة إلى البيانات الأولية. ثالثثاً: الاحتفاظ بالمعلومات الرياضية (Retaining mathematical information): وتشير إلى الذاكرة الرياضية للطالب، وقدرته على تعميم طرق حل المشكلات، ومخططات الحجج والبراهين، والاحتفاظ بها لفترة طويلة، فالطالب قد ينسى محتوى المشكلة التي حلها بعد وقت قصير ، لكن يجب إنب أن يتمتع بذ اكرة جيدة لطريقة حل ذلك النوع من المشكلات. وفي ضوء ما سبق، اهتمت الدراسة الحالية بالقدرة على معالجة المعلومات الرياضية، ومكوناتها التي تمثلت بالتعميم، والمنطق، والإنعكاسية، والمرونة؛ إذ اعتبرها كروتيسكي من خلال تجاربه العمليّة بأهها هي الأسـاس في تحديد الطلبة الذين يمتلكون القدرة الرياضية.

الدراسـات السـابقة: رغم تعدّد الدراسات التي تناولت التعلم القائم على المشروع في العلوم والدراسات الإجتماعية، إلاّ أنه لا يوجد حالياً سوى القليل من الأبحاث عن التعلم القائم على المشروع في مادة الرياضيات(Jacques, 2017). ومن هذه الدراسات: دراسـة مطرية (9 . . ب) والتي اتبعت المنهج شبه التجريبي بهدف التعرف على أثر التعلم المستند إلى طريقة المشروع في حل المشكلات والكتابة

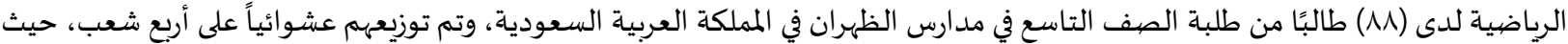
شكّلت شعبتان تضم كل منهما (r (Y) طالبًا المجموعة التجريبية، ودرست وفق التعلم المستند إلى المشروع، وشعبتان للمجموعة الضابطة تضيم كل 
منهما (r) طالبًا، ودرست بالطريقة الاعتيادية. وتوصيّلت الدراسة بعد تطبيق اختباري القدرة على حل المشكلات، والكتابة الرياضية إلى وجود فروق جوهرية في القدرة على حل المشكلات ومهارة الكتابة الرياضية لدى الطلبة تُعزى إلى طريقة التدريس، وذلك لصالح المجمموعة التجريبية التي درست وفق التعلم المستند إلى طريقة المشروع.

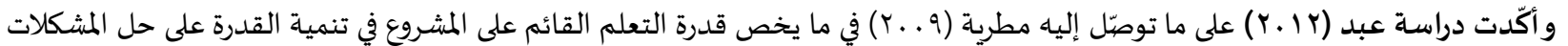
الرياضية، في دراستها التي تقصيّت أثر التعلم القائم على المشروع في تنمية القدرة على حل المشكلات والتحصيل الأكاديمي لدى طلبة السنة الثالثة

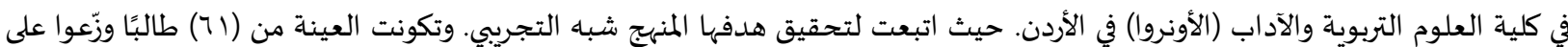

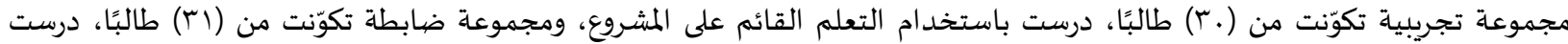
بالطريقة التقليدية. وتوصيّلت الدراسة بعد تطبيق اختباري القدرة على حل المشكلات والتحصيل الأكاديمي إلى الآثار الإيجابية للتعلم القائم على ملى مئل المشروع في كلٍ من تنمية القدرة على حل المشكلات، والتحصيل الأكاديمي. وفي سياق موضهوع الهندسة في الرياضيات، أجرت يو انقر (Uyangor, 2012) دراسة في تركيا تقصّت فيها أثر استخدام طريقة التعلم القائم على المشروع في تدريس وحدة المضلعات والهندسة المستوية في تحصيل طلبة الصف التاسع، وإتجاهاتهم نحو الرياضيات، حيث اتبعت المنهيج التجريبي بتصميم قبلي بعدي لمجموعة واحدة، وتكوّنت عينة الدراسة من (rr) طالبًا من طلبة الصف التاسع، درسوا لمدة أربعة أسابيع

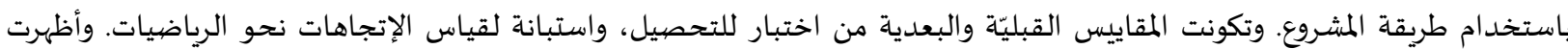

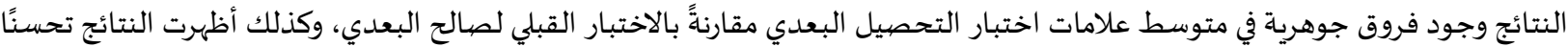
كبيرًا في الإتجاه نحو أرود فروف جوهرناه أمّا دراسة شن (Chin, 2014) فقد هدفت إلى التعرّف على أثر استخدام التعلم القائم على المشروع في أداء الطلبة في موضيوع الهندسة ومدى

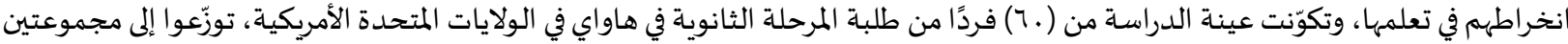

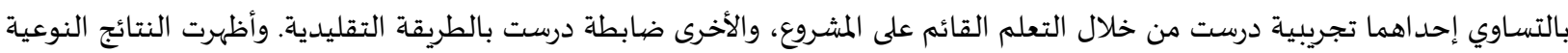

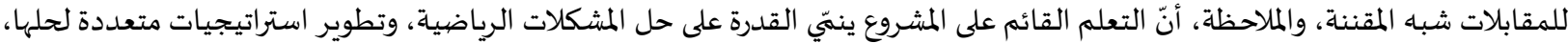

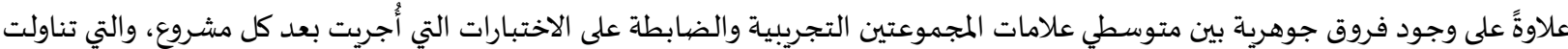
فهم المفاهيم، والمهارات الهندسية، وذلك لصالح المجموعة التجريبية. وفي السياق ذاته، أجرى سيرفانتزوهيمروكوزيكاناني (Cervantes, Hemmer \& Kouzekanani, 2015) دراسة اتبعت منهج المقارنة السببية،

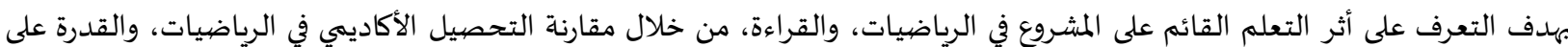
القراءة بين مدرستين في ولاية تكسـاس الأمريكية، إحداهما تستخدم التعلم القائم على المشروع، بينما الأخرى تستخدم الطريقة التقليدية. تكوّنت

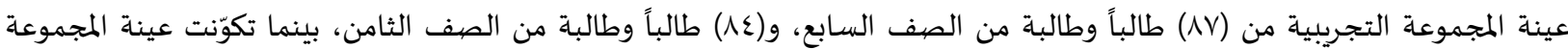
الضابطة من (.ع () طالباً وطالبة من الصف السابع، و(0.0 (1) طالباً وطالبة من الصف الثامن. وخضعوا جميعاً لاختبار الاستعداد الأكاديمي

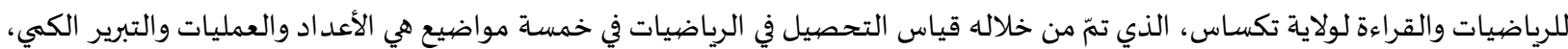
والأنماط والعلاقات والتبرير الجبري، والهندسة والاستدلال المكاني، والقياس، والإحصاء والاحتمالات. وأظهرت النتائج التي تخص الرياضيات فيات

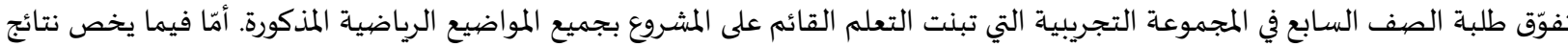

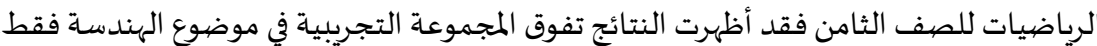
في حين ركّزت هزهوزي (17 ـ إ) في دراستها شبه التجريبية على تقصّي أثر التعلم المستند إلى المشروع في التفكير الرياضي والدافعية لدى عينة

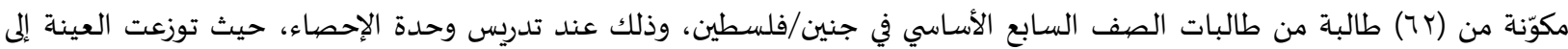

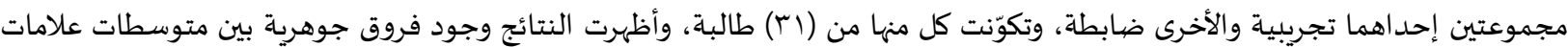

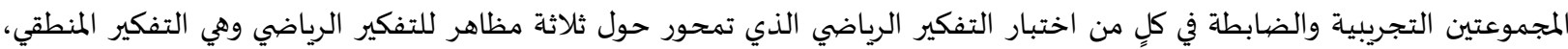

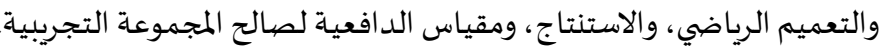
وأجرى جيرهانا ومارديانا وبراموديا (Gerhana, Mardiyana \& Pramudya, 2017) دراسة شباء تجريبية تقصّوا فهها فاعلية التعلم القائم على

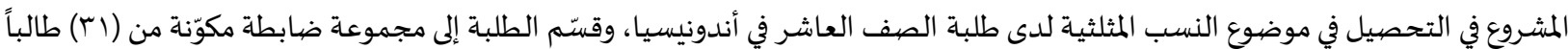

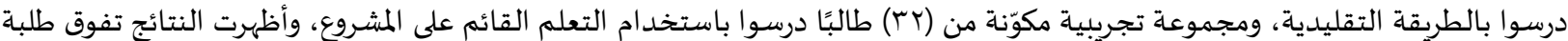
المجموعة التجربيية على المجموعة الضابطة في اختبار التحصيل. 
كما أجرى أومّا و إنعام وعزمي (Ummah, In’am \& Azmi, 2019) دراسة نوعياة، كان من أبرز أهد افها وصف تحسّن إبداع طلبة قسم تعليم

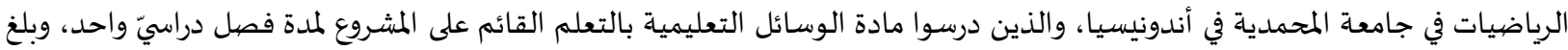

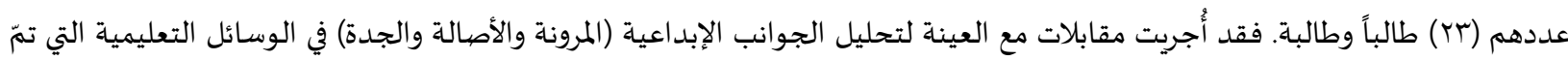
إنتاجها. وأظهرت النتائج وجود تحسّن في إبداع الطلبة في كلِّ من الجوانب الإبداعياة الثلاثة. بينما أجرت الهمص (19 ـ (19) دراسة هدفت إلى الكشف عن فاعلية برنامج تعليمي قائم على المشاريع لتنمية مهارات التفكير الرياضي لدى

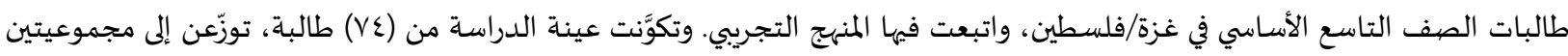

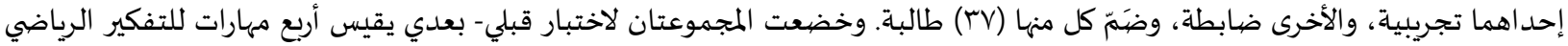

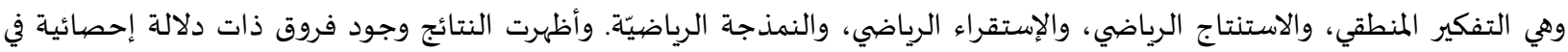

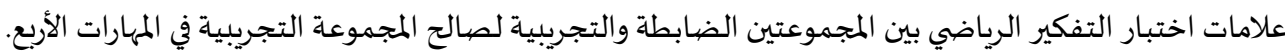

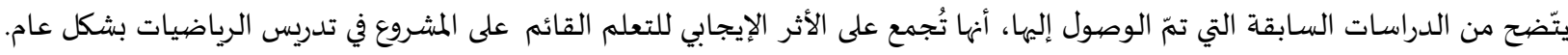

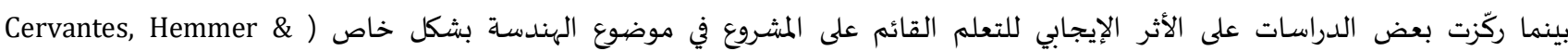
Gerhana, Mardiyana \& Pramudya, 2017) كما يتّضح أنّ معظم الدراسـات السابقلى (Kouzekanani, 2015; Chin, 2014; Uyanger, 2012

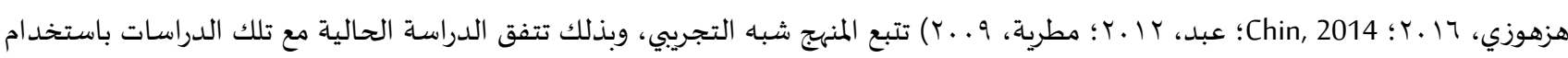

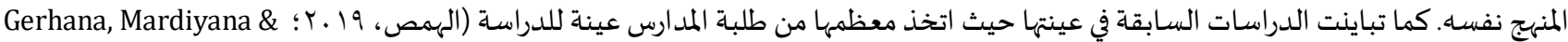

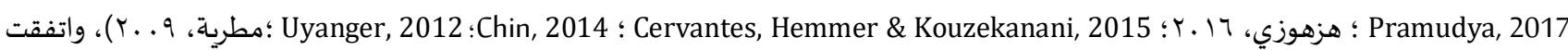

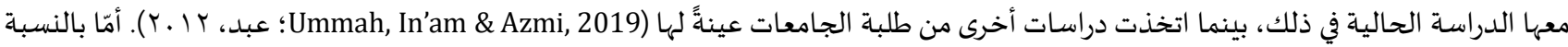

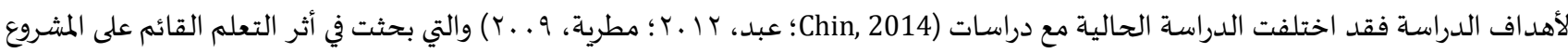
في القدرة على حل المشكلات بشكل عام، حيث ركّزت الدراسـة الحالية على أثر التعلم القائم على المشروع في القدرة الرياضية على معالجة المعلومات

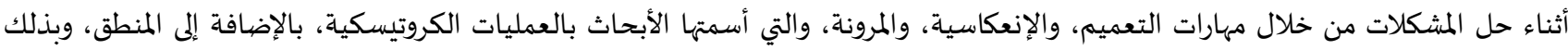

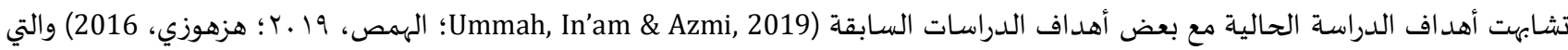

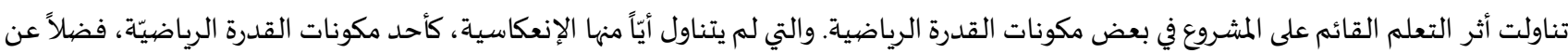

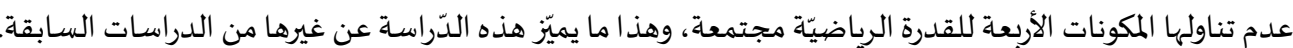

مشكلة الدراسة وأسئلتها:

يواجه تعليم الرياضيات في الأردن تحديات، ولعلّ واحدة من أهمّها هو صعوبة تعلم وفهم الطلبة لمادة الرياضيات، حيث يظهر ذلك جلياً من

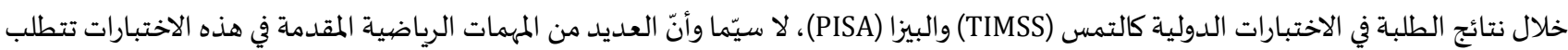

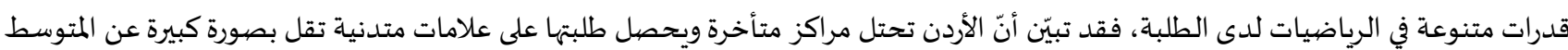
العام للعلامات على المستوى الدولي (Ababneh, Al-Tweissi \& Abulibdeh, 2016). كما لمست إحدى الباحثتين من خلال عملها كمعلمة رياضيات

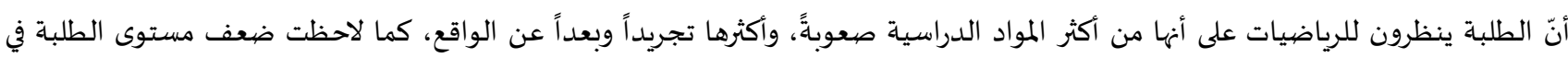

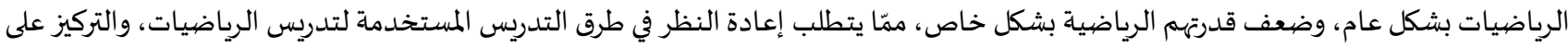
الطرق التي تساعد الطلبة على ربط الرياضيات بالواقع، وتطوير قدرتهم الرياضية.

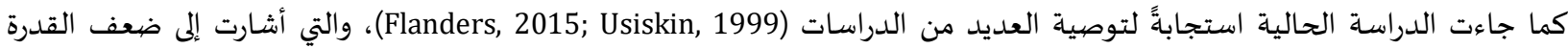

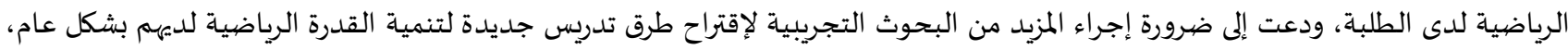

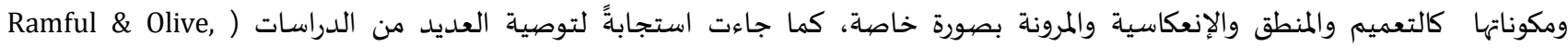

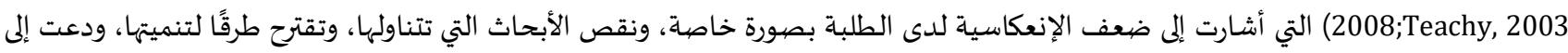

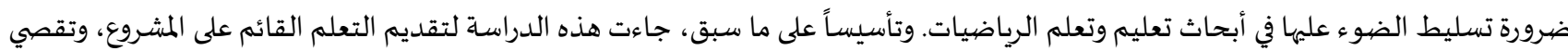
أثره في القدرة الرياضية ككل ومكوناتها (التعميم، المنطق، الإنعكاسية، المرونة إسية). وبالتحديد تجيب الدراسة عن السؤال الآتي:

ما أثر التعلم القائم على المشروع في القدرة الرياضية لدى طالبات الصيف التاسع الأسـاسي في الأردن؟

وتنبثق عناه الفرضيتان الآتيتان: مات آتران 
لا يوجد فرق ذو دلالة إحصائية (0., . =لع) بين المتوسطين الحسابيين لعلامات مجموعتي الدراسـة على اختبار القدرة الرياضية الكلّي البعدي يُعزى إلى طريقة التدريس (التعلم القائم على المشروع، الطريقة التقليدية).

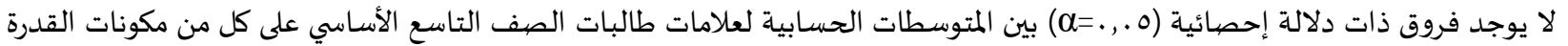
الرياضية (التعميم، المنطق، الإنعكاسية، المرونة) تُعزى لطريقة التدريس (التعلم القائم على المشروع، الطريقة التهاتية التقليدية).

أهمية الدراسـة:

تكتسب الدراسة الحالية أهميتها النظرية من ما ستضيفه من معرفة إلى المكتبة العالمية والعربية حول التعلم القائم على المشروع كونه منهجاً تعليمياً - تعلمياً - قائماً على التعامل مع مشاريع واقعية ترتبط بحياة الطلبة، فهذا المنهج يتيح بيئة تعلم للمفاهيم الرياضية تعتمد على مهيمات منهات

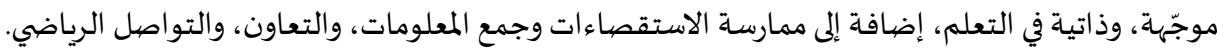
بينما تظهر الأهمية العملية لهذه الدراسة من إمكانية استفادة المعلمين منها لكسر الجمود والمللل الحاصل في حصديه حصد الرياضيات التقليدية

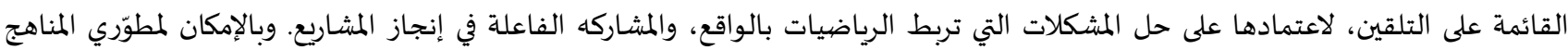
الإستفادة من هذه الدراسة في تصميم وحدات دراسية تستند الى التعلم القائم على المشروع بحيث تكامل بين الرياضيات وعدة مواد دراسية أخرى،

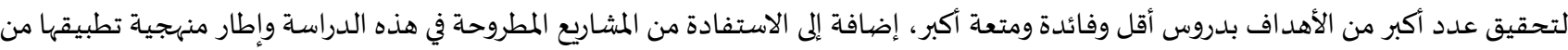

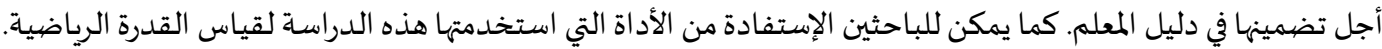

\section{مصطلحات الدراسـة وتعريفاتها الإجر ائية}

المشروع: نشاط يقوم على هدف محدّد، ينفّذ في مناخ اجتماعي حقيقي، ويؤدي إلى حل مشكلة حياتية معقدة باستخدام المعرفة الرياضية السابقة

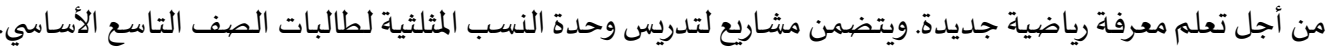

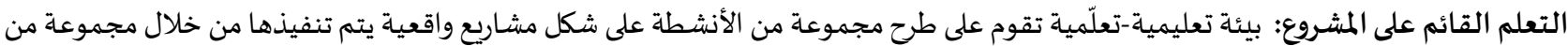

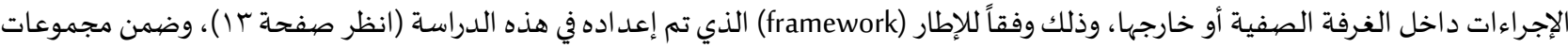

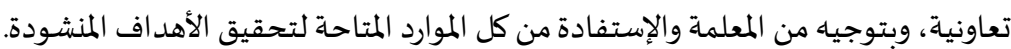

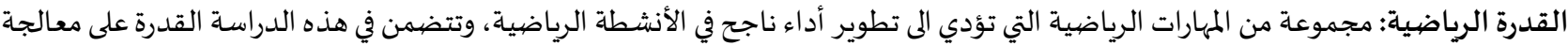

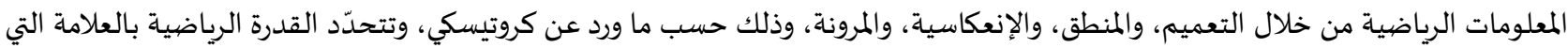
تحصل عليها الطالبة نتيجة تعرضها لاختبار القدرة الرياضية الذي أعدّ لهذا الغرض. وفي ما يلي تعريف لكل مكون من مكونات القدرة الرياضية: التعميم: القدرة على صياغة وتوسيع عبارة رياضية لتصبح أعم وأشمل بناءً على حالات خاصية. المنطق: القدرة على تفسير وتحليل البيانات المعطاة وعمل سلسلة من الاستنتاجات المنطقية المدعِّمة بالتبرير للوصيول إلى حل للمشكلة الرياضياة.

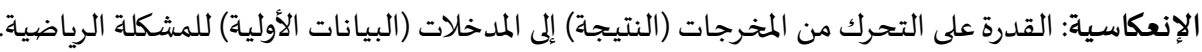
المرونة: القدرة على حل المشكلة الرياضية بأكثر من طريقة اعتمادً على تصورات مختلفة للأفكار الرياضية.

محدددات الدراسـة: تتحدّد نتائج الدراسة باقتصارها على عينة من طالبات الصف التاسع الأسـاسي الملتحقات في إحدى المدراس الحكومية التابعة لمديرية التربية

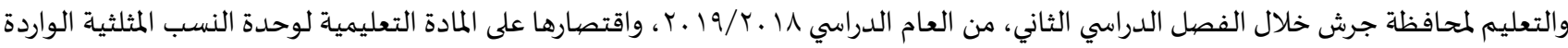

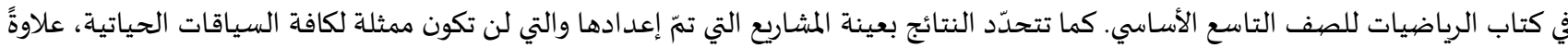

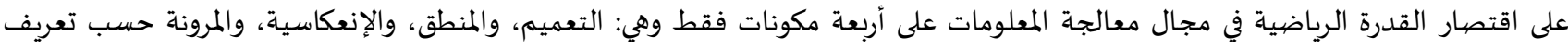

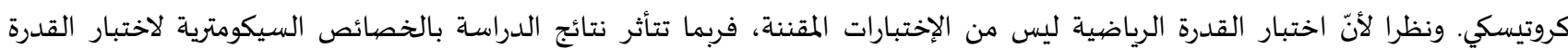

الرياضيّة، إضافة إلى تأثرها بقاعدة تصحيح الاختبار (Rubric).

\section{الطريقة والإجراءات:}

منهجية الدراسـة:

استُخدم المنهج شبه التجريبي بتصيميم قبلي- بعدي لمجموعتين، وذلك من أجل تقصّي أثر التعلم القائم على المشروع في القدرة الرياضية لدى لدي طالبات الصف التاسع الأساسي. وبذلك تتحدّد متغيرات الدراسـة بالمتغير المستقل وهو طريقة التدريس بمستويهيها التعلم القائم على المشروع، والطريقة 
التقليدياة، والمتغيرات التابعة وهي أداء الطالبات على اختبار القدرة الرياضية بشكل عام، والأداءات على كل مكون من مكوناتها (التعميم، المنطق، الإنعكاسية، المرونة).

عينة الدراسـة:

تمّ اختيار (V乏) طالبة من الصف التاسع الأساسي الملتحقات بمدرسة بليلا الثانوية الشاملة للبنات، التابعة لمديرية التربية والتعليم لمحافظة

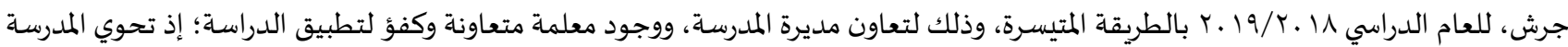
شعبتين فقط للصف التاسع الأساسي، وتمّ بالتعيين العشوائي تحديد إحدى الشعبتين لتكون المجموعة التجريبية، وبلغ عدد أفرادها (T) طالبة،

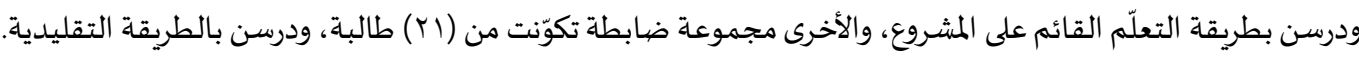

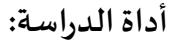

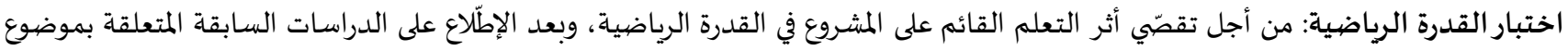
القدرة الرياضية ; (Dougherty, B.Bryant, D.Bryant, Darrough \& Pfannenstiel, 2015; Flanders, 2015; Maharani, 2014; Dindyal, 2007 (Trutetskii, 1976) بالإضافة إلى أسئلة تيمس (TIMSS)، تمّ إعداد اختبار القدرة الرياضية بأبعة مكونات كما حدّدها كروتيسكي وهي التعميم،

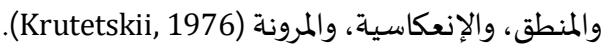

الصيورة الأولية للاختبار: تكوّن الإختبار بصورته الأوّلّيّة من (7 (1) فقرة مقالية، بحيث اشتمل كل مكوّن من مكونات القدرة الرياضية على (ع) فقرات.

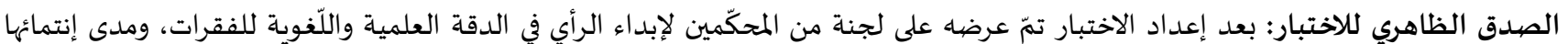
لمكونات القدرة المختلفة، وملاءمتها لمستوى الصف التاسع الأساسي، وقد تمّ الأخذ بكافة الملحوظات والإقتراحات المقدّمة من المحكّمين، وتمّ تعديل

بعض الفقرات، مع المحافظة على عددها (7 1 ) فقرة موزّعة على أربع فقرات لكل مكوّن من مكوّنات القدرة الرياضياة.

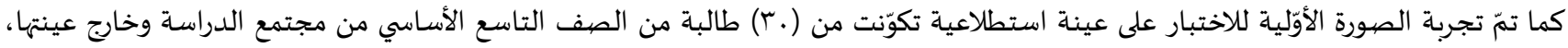

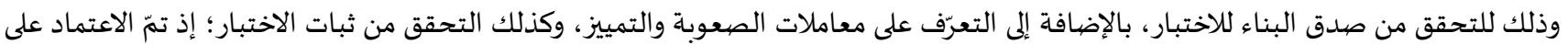
برمجية (SPSS) في التحقق من كل ما سبق. بالإضافة لاحتساب الزمن المناسب للإختبار، وفي ما يلي تفصيل لذلك:

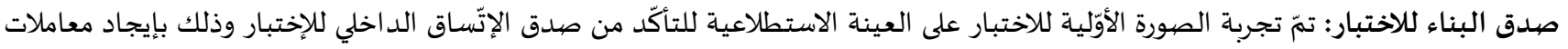
الإرتباط بين الأداء على كل فقرة مع المكون الذي تقيسه، ومع الإختبار الكلي، إضافة إلى الإرتباطات البينية لمكونات القدرة الرياضية الأربعة، وكذلك الإنك

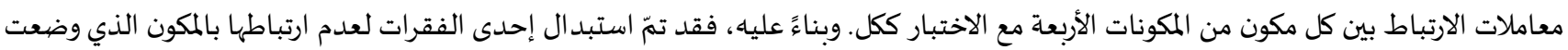

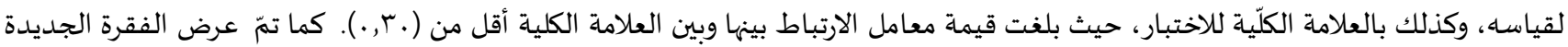
على العينة الاستطلاعية للتأكد من ارتباطها بالمكون الذي تقيسه وكذلك بالاختبار الكلي. وبذلك بلغت معاملات الارتباط بين الفقرات بعد التعديل

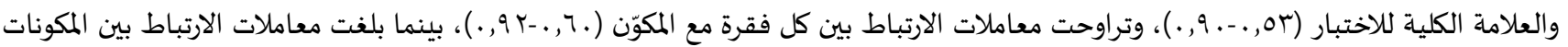

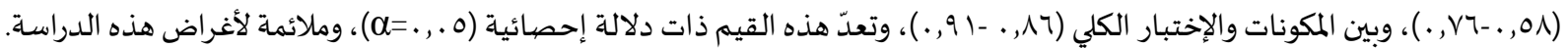

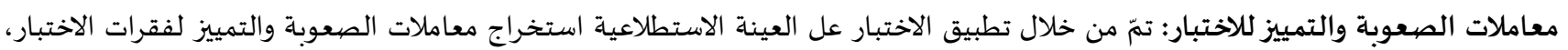

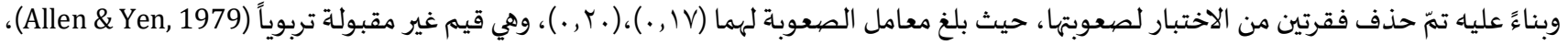

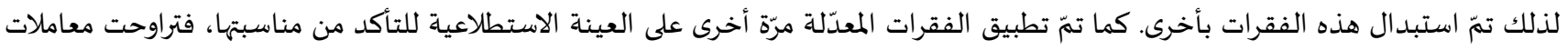

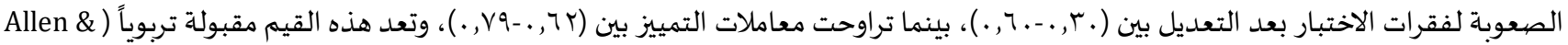

(Yen, 1979 )، وملائمة لأغراض الدراسة.

ثبات الاختبار: تمّ من خلال تطبيق الاختبار على العينة الاستطلاعلاعية التحقق من ثبات اختبات التبار القدرة الرياضية المعدّل من خلال حساب معادلة

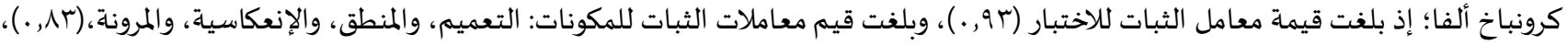

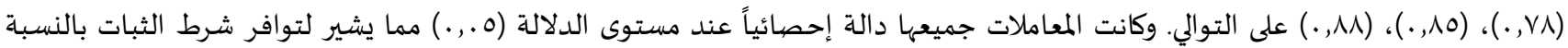

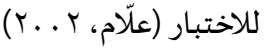
الزمن المناسب للاختبار: تمّ من خلال تطبيق الاختبار على العينة الاستطلاعية احتساب الزمن المناسب للإختبار، وذلك من خلال حساب متوسط

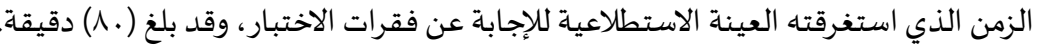

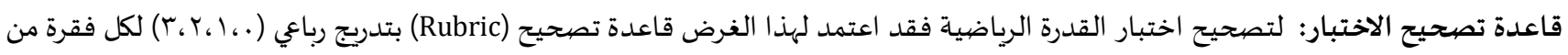
فقرات الاختبار، كما هو مبين في الجدول ( ) أدناه.وبذلك بلغت العلامة القصيوى للاختبار ككل (^ع)، والصغرى (.). كما بلغت العلامة لكل مكون من

مكونات القدرة الرياضية (Y ( ). 


\begin{tabular}{|c|c|c|c|c|}
\hline \multicolumn{5}{|c|}{ جدول (1): قاعدة تصحيح اختبار القدرة الرياضيّة } \\
\hline لم يتوصل إلى تعميم & يتوصل إلى تعميم خاطئ & يتوصل إلى التعميم الصحيح بدون تبرير لكيفية & 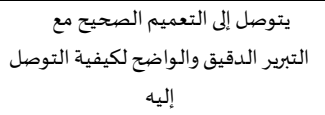 & التعميم \\
\hline $\begin{array}{c}\text { - إعطاء حل غير قائم على التحليل أو التفسير للمعلومات المقدمة إليه. } \\
\text { ـ لا حل. }\end{array}$ & 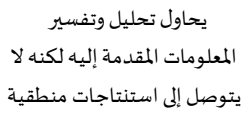 & يحلل ويفسر المعلومات المقدمة إليه ويتوصل إلى & يدلل ويفسر المعلومات المقدمة إليه & المنطق \\
\hline يحلّ المسألة بطريقة واحدة خاطئة. & 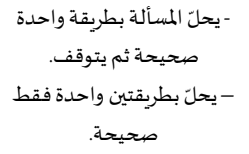 & 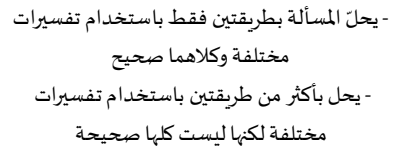 & يحاسل المسألة بأكثر من طريقتين & 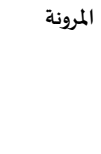 \\
\hline لا يوجد محاولات للحل & 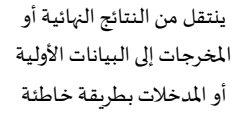 & 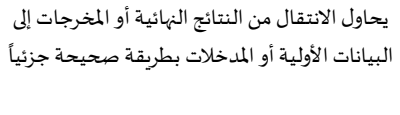 & 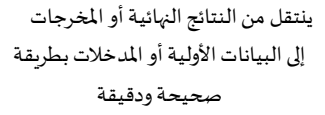 & الإنعكاسية \\
\hline
\end{tabular}

إعداد المادة التعليمية حسب التعلم القائم على المشروع:

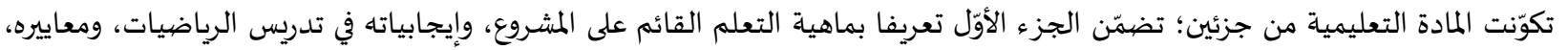

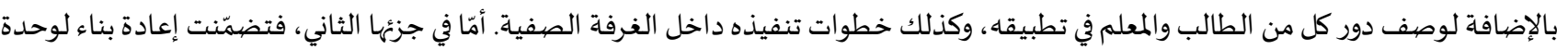

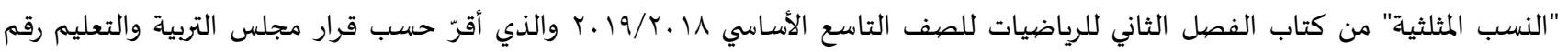

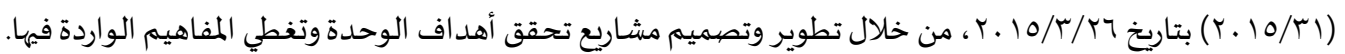

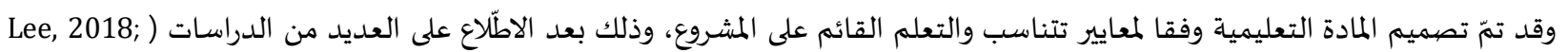

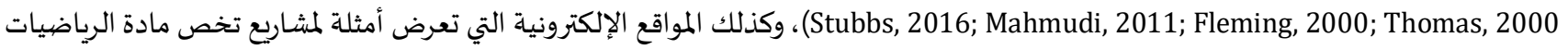
مثل (Pinterest، TeachThought، Curriki Geometry)، وتضمّنت أربعة مشاريع هي مشروع السخان الشمسي ويغطي موضوعات جيب الزاوية الحادة وجيب تمام الزاوية الحادة وظل الزاوية الحادة، ومشروع أنا معلم ويغطي موضوع العلاقات بين النسب المثلثية، ومشروع معرض الفنون ويغطي مئي

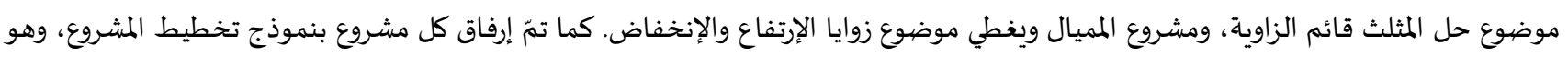

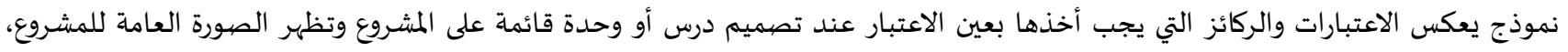

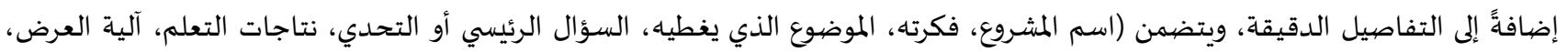

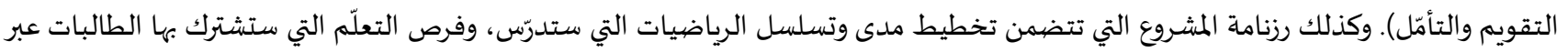

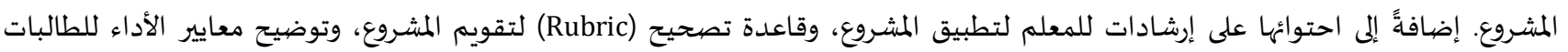

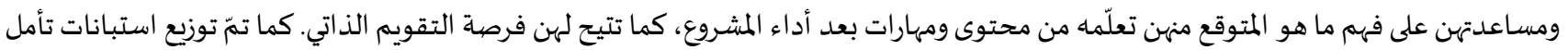

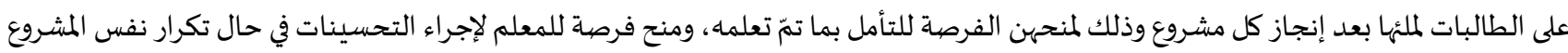

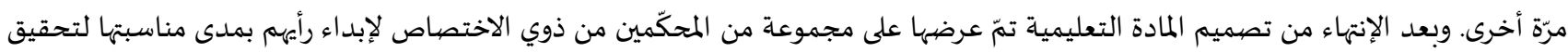

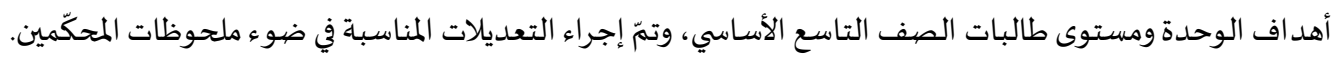

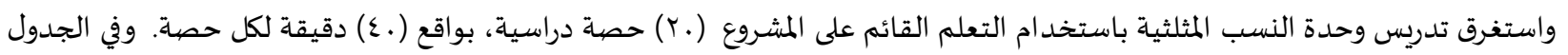

جدول (r): الخطة الزمنية لتدريس وحدة النسب المثلثية باستخدام التعلم القائم على المشروع

\begin{tabular}{|c|c|}
\hline 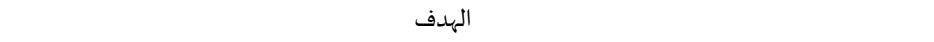 & عدد الحصص \\
\hline تعريف الطالبات بالتعلم القائم على المشروع وطرح أمثلة محلولة & 1 \\
\hline تدربب الطالبات على التعلم القائم على المشروع من خلال تنفيذ مشروع من خارج المشاريع التي أُعِدِت للدراسة & $\varepsilon$ \\
\hline 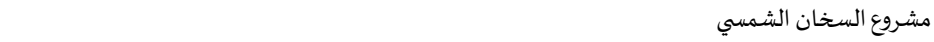 & 0 \\
\hline مشروع أنا معلم & $r$ \\
\hline 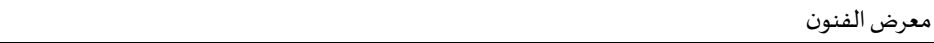 & r \\
\hline 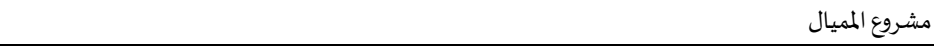 & r \\
\hline التأمّل بما تمّّ تعلّمها & 1 \\
\hline
\end{tabular}


أمّا بالنسبة لمراحل أوخطوات التعلم القائم على المشـروع التي تمّّ تطبيقها داخل الغرفة الصفية فهي تتلخّص في الإطار الذي تمّ إعداده بالإعتماد على دراسة جيرهانا ومارديانا وبراموديا (Gerhana, Mardiyana \& Pramudya, 2017)، وما أشار إليها لي (Lee, 2018)، والوارد في الشكل (I):

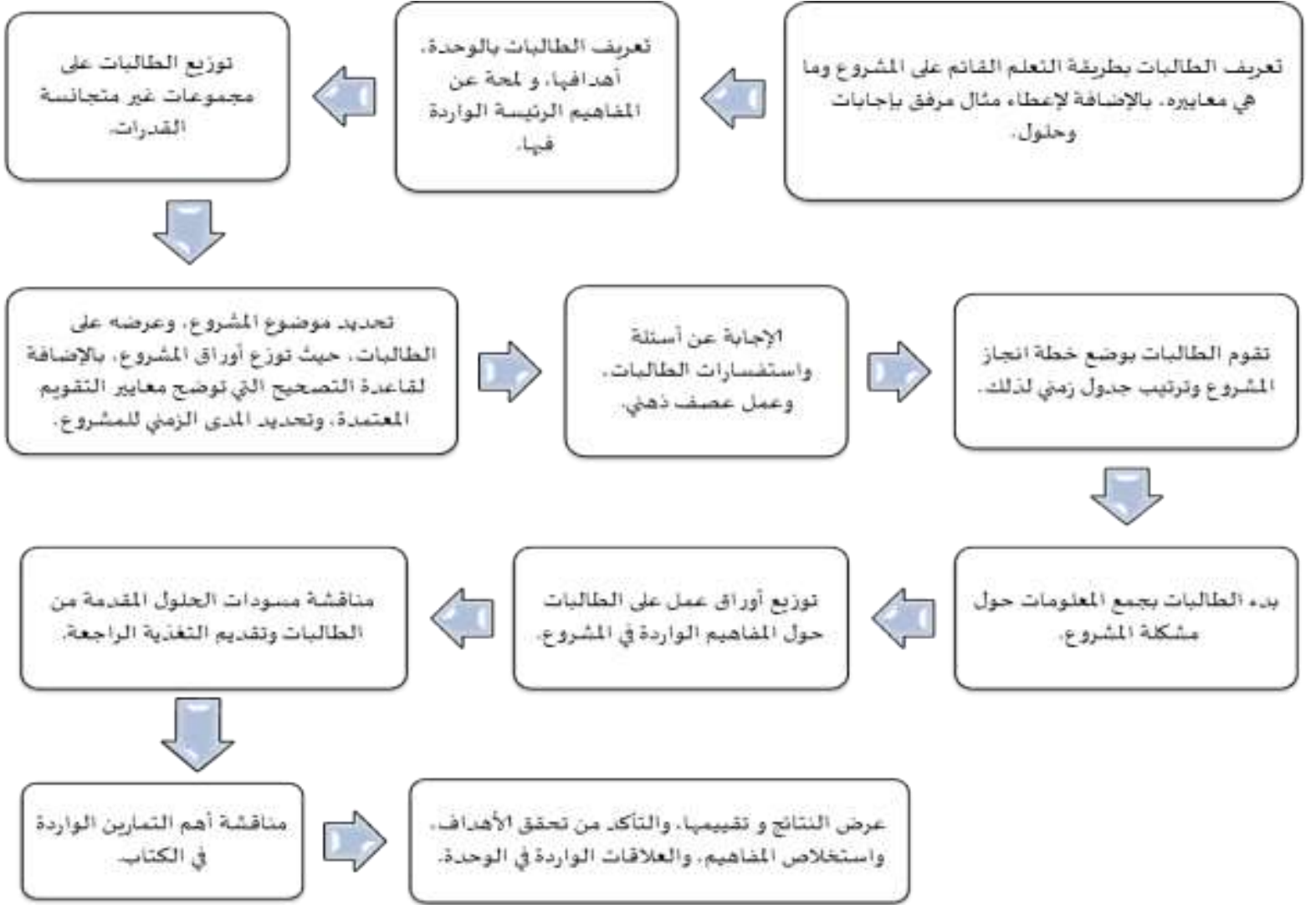

شكل(1): الإطار الذي يوضّح خطوات استر اتيجية التعلم القائم على المشروع التي تمّ تطبيقها داخل الغرفة الصفيّة

تكافؤ مجموعتي الدراسة:

وللتحقق من تكافؤ المجموعات تمّ تطبيق اختبار القدرة الرياضية بصورته الهائية قبل البدء بإجراء الدراسـة على المجموعتين التجرببية والضابطة، وذلك ضمن جلستين مدة كل منهما (.ع) دقيقة، وتمّ استخراج المتوسطات الحسابية والإنحرافات المعيارية لعلامات أفراد الدراسة تبعًا

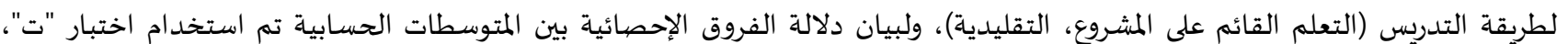
والجدول (r) يوضح ذلك.

\begin{tabular}{|c|c|c|c|c|c|c|c|}
\hline الإحصائية الدلالة & درجات الحرية & قيمة "ت" & الإنحراف المعياري & المتوسط الحسي & العدد & طريقة التدريس & \\
\hline \multirow[t]{2}{*}{. } & \multirow[t]{2}{*}{$\varepsilon 0$} & \multirow[t]{2}{*}{$1, .9$} & $0, \varepsilon \varepsilon$ & 1,94 & rT & PBL & \multirow[t]{2}{*}{ التعميم قبلي* } \\
\hline & & & $\varepsilon, r$. & V,r & rI & التقليدية & \\
\hline \multirow[t]{2}{*}{.,AVr } & \multirow[t]{2}{*}{ ¿o } & \multirow[t]{2}{*}{1,71} & E,r & $V, V T$ & YT & PBL & \multirow[t]{2}{*}{ المنطق قبلي* } \\
\hline & & & Tr, & $7, .0$ & rI & التقليدية & \\
\hline \multirow[t]{2}{*}{., $9 \leqslant \varepsilon$} & \multirow[t]{2}{*}{$\varepsilon 0$} & \multirow[t]{2}{*}{., .0} & $\varepsilon, \wedge \Lambda$ & $1,0 \leqslant$ & r & PBL & \multirow[t]{2}{*}{ الإنعكاسية قبلي } \\
\hline & & & $r, 0 \varepsilon$ & $v, 9 T$ & rI & التقليدية & \\
\hline \multirow[t]{2}{*}{., Vro } & \multirow[t]{2}{*}{$\varepsilon 0$} & \multirow[t]{2}{*}{$1, r 9$} & $\varepsilon, 9 \varepsilon$ & 1,10 & r & PBL & \multirow[t]{2}{*}{ المرونة قبلي* } \\
\hline & & & $r, 17$ & $V, r \varepsilon$ & rI & التقليدية & \\
\hline \multirow[t]{2}{*}{., 9.9} & \multirow[t]{2}{*}{$\varepsilon_{0}$} & \multirow[t]{2}{*}{$r, \ldots$} & $1,9 r$ & $r \varepsilon, . \varepsilon$ & r & PBL & \multirow[t]{2}{*}{ القدرة الرياضية قبلي ** } \\
\hline & & & 9,90 & TM,00 & rI & التقليدية & \\
\hline
\end{tabular}

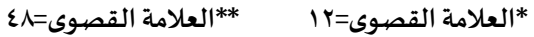


يتبين من الجدول (r) عدم وجود فروق ذات دلالة إحصائية (0., . م= م) بين المتوسطات الحسابية لمجموعتي الدراسة في جميع مكونات القدرة الرياضية وفي الدرجة الكلية، ممّا يشير إلى تكافؤ مجموعتي الدراسة بالنسبة لاختبار القدرة الرياضية القبلي. إجراءات الدراسـة:

ا ـ. إعد اد أدوات الدراسة (المادة التعليمياة، اختبار القدرة الرياضية)، والتحقق من صدقهها وثباتها. r. الحصول على كتاب تسهيل مهمة من أجل تطبيق التجربة في المدرسة، واختيار عينة الدراسة.

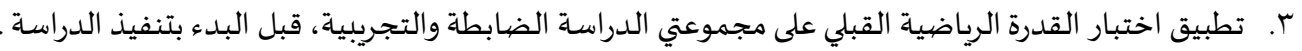

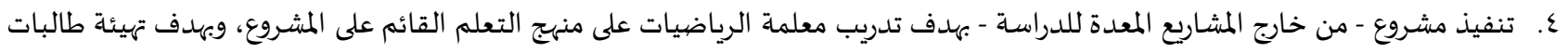

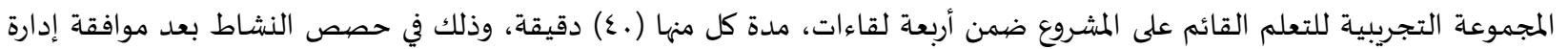
المدرسة، وكان مضمون المشروع في تدريس الهندسة خارج نطاق النسب المثلثية.

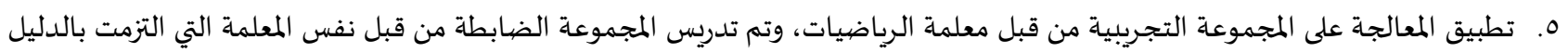

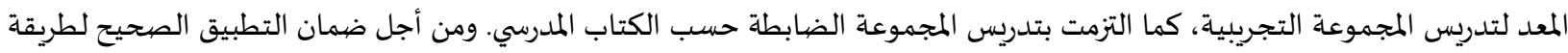

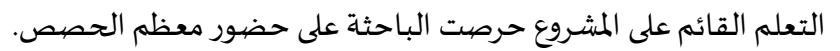

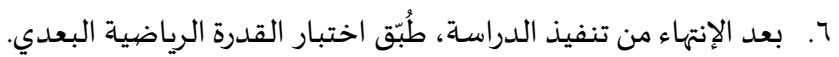

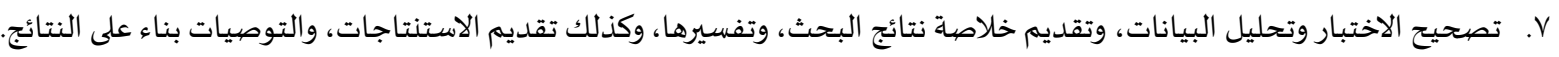

المعالجات الاحصيائية:

لتحليل بيانات الدراسـة، تمّ حساب المتوسطات الحسابية والإنحرافات المعيارية لعلامات أفراد مجموعتي الدراسة تبعًا لطريقة التدريس (التعلم

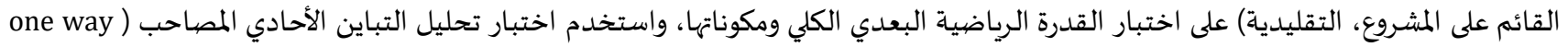

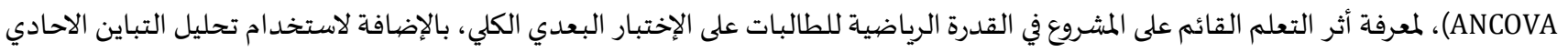

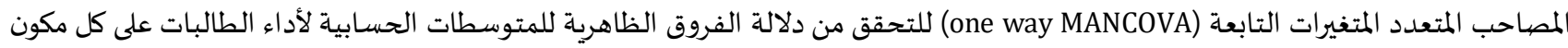
من مكونات اختبار القدرة الرياضية البعدي. نتائج الدراسـة ومناقشتهـا: مونات للإجابة عن سؤال الدراسة والذي يهدف إلى تقصّي أثر التعلم القائم على المشروع في القدرة الرياضية لدى طالبات الصفف التاسع الأساسي، تمّ اختبار الفرضية الأولى ونصها " لا يوجد فرق ذو دلالة إحصائية (ه . .ع=م) بين المتوسطين الحسابيين لعلامات مجموعتي الدراسة على اختبار القدرة

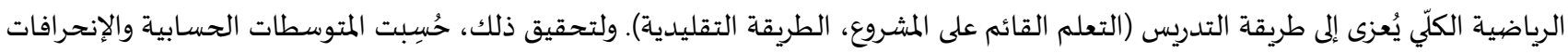

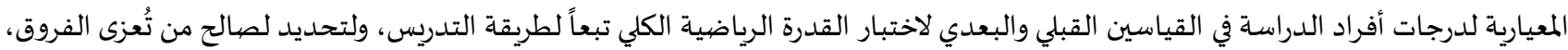

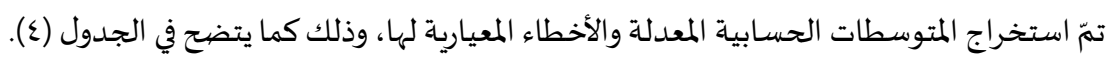

جدول (ع): المتوسطات الحسابية والانحر افات المعيارية للقدرة الرياضية لدى طالبات الصف التاسع الأساسي للقياسين القبلي والبعدي تبعاً لطريقة

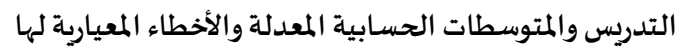

\begin{tabular}{|c|c|c|c|c|c|c|c|}
\hline & & \multicolumn{2}{|c|}{ القياس البعدي } & \multicolumn{2}{|c|}{ القياس القبلي } & \multirow[b]{2}{*}{ العدد } & \multirow[b]{2}{*}{ طريقة التدريس } \\
\hline المعياري & المتوسط الحسـابي & المعياري & الحستوسط المسبي & المعياري & الحستوسط الحسب & & \\
\hline., .01 & $\sum 1, \wedge 9$ & $0, r \varepsilon$ & $\varepsilon ., 0$. & $\Lambda, 94$ & $r \varepsilon, \cdot \varepsilon$ & rY & PBL \\
\hline., .01 & $Y V, O$. & $r, r)$ & $\lceil\wedge, \wedge 1$ & 9,90 & $r \Lambda, 00$ & r) & التقليدية \\
\hline
\end{tabular}

ييتضح من الجدول (ع) وجود فروق ظاهرية بين المتوسطات الحسابية للقدرة الرياضية لدى طالبات الصف التاسع الأساسي في القياس البعدي لاختبار القدرة الرياضية وفقاً لطريقة التدريس (التعلم القائم على المشروع، الطريقة التقليدية). ولمعرفة فيما إذا كانت هذه الفروق الظاهرية ذات

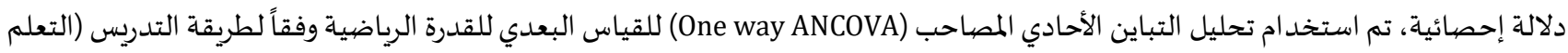
القائم على المشروع، الطريقة التقليدية) بعد تحييد أثر القياس القبلي، ويبين الجدول (0) نتائج التحليل. 
جدول (0): نتائج تحليل التباين الأحادي المصاحب (One way ANCOVA) للقياس البعدي للقدرة الرياضية لدى طالبات الصف التاسع الأساسي ككل وفقاً لطريقة التدريس بعد تحييد أثر القياس القبلي

\begin{tabular}{|c|c|c|c|c|c|c|}
\hline مربع إيتا ص2 & مستوى الدلالة & قيمة ف & متوسط مجموع & درجات الحرية & مجموع المربعات & مصدر التباين \\
\hline & .,. Vo & qV, ro & $1 . V r, V 7$ & 1 & $1 . V r, V 7$ & القياس القبلي \\
\hline \multirow[t]{3}{*}{., $\vee १ १$} & $\ldots$ & $|r|, V r$ & $\mid r \varepsilon r, 7 \varepsilon$ & 1 & $\mid r \varepsilon r, T \varepsilon$ & طريقة التدربس \\
\hline & & & $11, . r$ & $\varepsilon \varepsilon$ & $\varepsilon \wedge 0, r \varepsilon$ & الخطأ \\
\hline & & & & $\varepsilon 7$ & $r q .1,7 \varepsilon$ & الكلي \\
\hline
\end{tabular}

يبيّن الجدول (0) وجود فرق ذي دلالة إحصائية (P (P > P) في القدرة الرياضية لدى طالبات الصف التاسع الأساسي وفقاً لطريقة التدريس

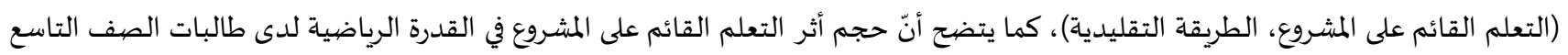

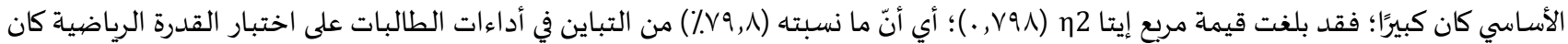

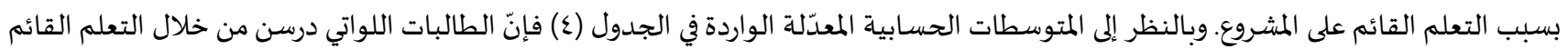

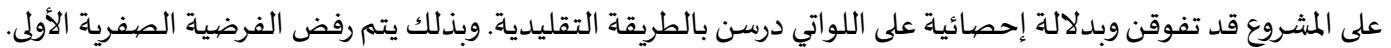

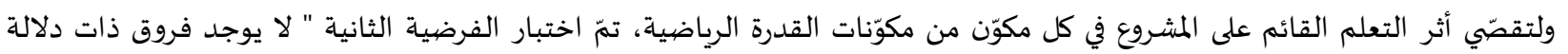

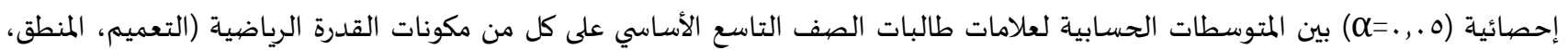

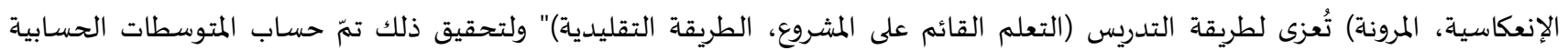
والإنحرافات المعيارية للقياسين القبلي والبعدي لمكونات القدرة الرياضية لدى طالبات الصف التهرئاسع الأساسي وفقاً لطريقة التدريس (التعلم القائم على المشروع، الطريقة التقليدية)، كما تمّّ حساب المتوسطات الحسابية المعدّلة والأخطاء المعيارية لها، كما هو مبين في الجدول (7). جدول (7): المتوسطات الحسابية والانحر افات المعيارية للقياسين القبلي والبعدي لمكونات القدرة الرياضية لدى طالبات الصف التاسع الأساسي

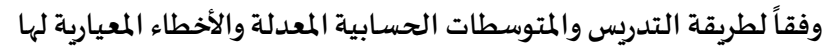

\begin{tabular}{|c|c|c|c|c|c|c|c|c|}
\hline \multirow{3}{*}{ المعياري الخطأ } & \multirow{3}{*}{ المتوسط المسابي } & \multicolumn{2}{|c|}{ القياس البعدي } & \multicolumn{2}{|c|}{ القياس القبلي } & \multirow[t]{3}{*}{ العدد } & \multirow{3}{*}{ طريقة التدرسس } & \multirow[t]{3}{*}{ المكونات } \\
\hline & & الإنحراف & المتوسط & الإنحراف & المتوسط & & & \\
\hline & & المعياري & الحسابي & المعياري & الحسابي & & & \\
\hline.,.$\wedge 7$ & $1 ., 94$ & 0,91 & $9, V r$ & $0, \varepsilon \varepsilon$ & 1,94 & r & PBL & \multirow[t]{2}{*}{ التعميم } \\
\hline.,.$\wedge 7$ & $V, \wedge 9$ & $\varepsilon, T_{T}$ & $\vee, \varepsilon \wedge$ & $\varepsilon, \Gamma$. & V,r & ri & التقليدية & \\
\hline., .94 & $q, \vee \wedge$ & 0,11 & $1 ., T V$ & $\varepsilon, \pi r$ & $V, V r$ & ry & PBL & \multirow[t]{2}{*}{ المنطق } \\
\hline., .95 & T, Tr & r,人r & $7, V 7$ & T, TH & $7, .0$ & rI & التقليدية & \\
\hline., $.7 r$ & $1 ., 7 r$ & $0,9 V$ & $1 ., .1$ & $\varepsilon, \wedge \Lambda$ & $1,0 \varepsilon$ & $r 7$ & PBL & \multirow[t]{2}{*}{ الإنعكاسية } \\
\hline . . . & $7,1 r$ & $r, T V$ & $V, O Y$ & $r, 0 \leqslant$ & $v, q r$ & rI & التقليدية & \\
\hline.,.$\wedge r$ & 1.07 & 0,0 r & $1 ., \varepsilon r$ & $\varepsilon, 9 \varepsilon$ & $1, \wedge 0$ & ry & PBL & \multirow[t]{2}{*}{ المرونة } \\
\hline .,.人r & $V, Y Y$ & $r, .0$ & $V, .0$ & $r, 17$ & $V, Y \varepsilon$ & rI & التقليدية & \\
\hline
\end{tabular}

يلحظ من الجدول (7) وجود فروق ظاهرية بين المتوسطات الحسابية لعلامات مجموعتي الدراسة في القياس البعدي لمكوّنات القدرة الرياضية

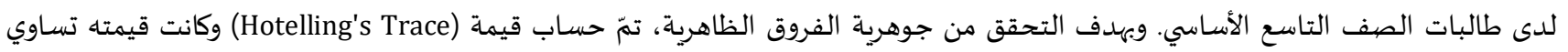

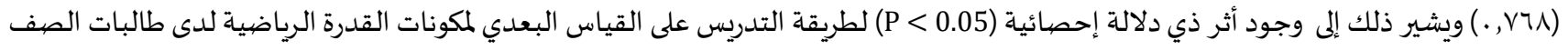

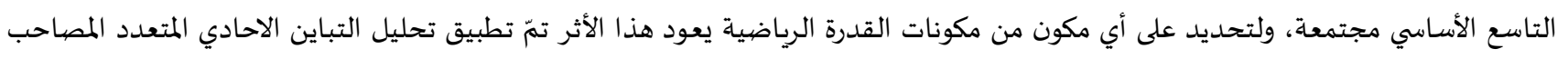

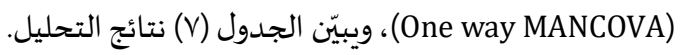


جدول(V)): تحليل التباين الأحادي المصاحب المتعدّد (one way MANCOVA) لأثر طريقة التدريس على القياس البعدي لكل مكون من مكونات القدرة الرياضية

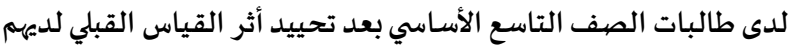

\begin{tabular}{|c|c|c|c|c|c|c|c|}
\hline $\begin{array}{c}\text { حجم الأثر }{ }^{2} \\
\eta^{2}\end{array}$ & الدلالة & ف & وسط مجموع & درجة الحرية & مجموع المربعات & المكون & مصدر التباين \\
\hline & ., $\mathrm{YNI}$ & $r T, \varepsilon V$ & $7 \gamma, 0\}$ & 1 & $7 \gamma, 0\}$ & التعميم بعدي & القبلي (المصاحب) \\
\hline &., .99 & 19,01 & $\varepsilon \wedge, q \vee$ & 1 & $\{\wedge, 9 \vee$ & المنطق بعدي & \\
\hline &., 17 & $10, r 1$ & $9 \mathrm{q}, \mathrm{ro}$ & 1 & $9 \mathrm{q}, \mathrm{ro}$ & الانعكاسية بعدي & \\
\hline & . ז人. & $\varepsilon 7, . V$ & NY,or & 1 & $\lambda v, o r$ & المرونة بعدي & \\
\hline ., &.,$\ldots$ & $T Y, Y \wedge$ & $1 T 9,0 \varepsilon$ & 1 & $1 T 9,0 \varepsilon$ & التعميم بعدي & طريقة التدريس \\
\hline., 010 & $\ldots r$ & $r Y,\{\Lambda$ & $07, \varepsilon r$ & 1 & $07, \varepsilon r$ & المنطق بعدي & \\
\hline 政 & ,., & $r 1, . \varepsilon$ & $r 0, r q$ & 1 & $r 0, r q$ & الانعكاسية بعدي & \\
\hline 年, 799 &,$\ldots$ & $r \mu, \Lambda\rceil$ & $7 \varepsilon, r \varepsilon$ & 1 & $7 \varepsilon, r \varepsilon$ & المرونة بعدي & \\
\hline & & & $r, . \Lambda$ & \&1 & 85.40 & التعميم بعدي & الخطأ \\
\hline & & & $r, 01$ & \&1 & 1. r, Vo & المنطق بعدي & \\
\hline & & & $1,1 \varepsilon$ & \&1 & $\varepsilon\rceil, \lambda \vee$ & الانعكاسية بعدي & \\
\hline & & & 1,9 . & \&1 & $V V, \Lambda 0$ & المرونة بعدي & \\
\hline & & & & $\leqslant 7$ & $r \Lambda r, \varepsilon \Lambda$ & التعميم بعدي & الكلي المصحح \\
\hline & & & & $\varepsilon 7$ & $r \cdot 1,10$ & المنطق بعدي & \\
\hline & & & & $\varepsilon 7$ & $|v 9,0|$ & الانعكاسية بعدي & \\
\hline & & & & $\varepsilon 7$ & YTQ,VY & الممرونة بعدي & \\
\hline
\end{tabular}

يتضح من الجدول (V) وجود فروق ذات دلالة إحصائية (P (P > P) بين المتوسطات الحسابية لعلامات طالبات الصف التاسع الأساسي على

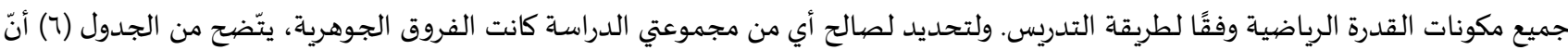
المتوسطات الحسابية المعدّلة كانت لصالح الطالبات اللواتي درسن وفق التعلم القائم على المشروع، كما يتّضح بأنّ حجم الأثر لمكونات القدرة الرياضية

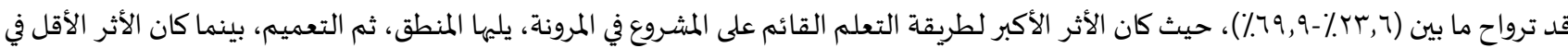

مناقشـة النتائج استناداً لما أظهرته نتائج الدراسة، يمكن القول بوجود أثر إيجابي وجوهري للتعلم القائم على المشروع في القدرة الرياضية بمكوناتها الأربعة

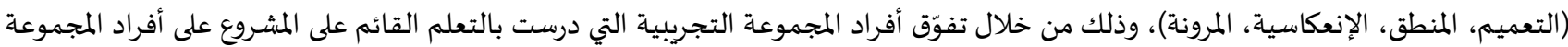
الضابطة والتي درست بالطريقة التقليدية في مكونات القدرة الرياضية الأربعة. ويمكن تفسير هذه النتيجة بأنّ التعلم القائم على المشروع أتاح الفرصية

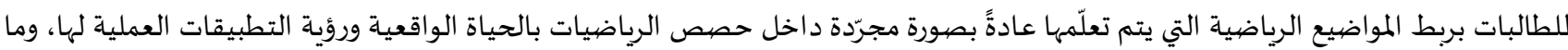
يؤكد ذلك تأملات الطالبات "أصبحت أرى الرياضيات بصيورة مختلفة بعد أن كان كله قوانين مش [ليست] مفهوهة أصبحت أشيوفه [أراه] بعين [من

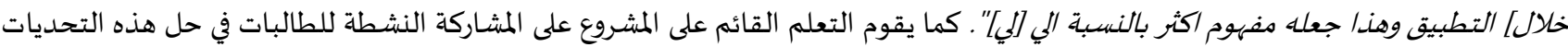

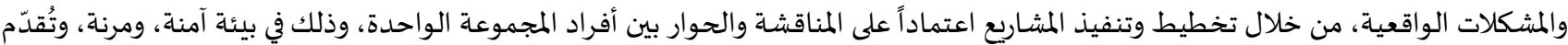
فيها التغذية الراجعة باستمرار. وما يؤكد ذلك ما ورد في استبانات التأمل التي كانت توزّع على الطالبات بعد كل مشروع، فكتبت إحدى الطالبات: "

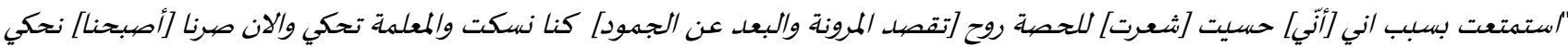
والمعلمة تسمع وتتابع اذا حكينا [كلامنا] صح [صحيح] ولا [أم] لا ، وتذكر أخرى:" استمتعت بسبب أن الحصبة لمرتكن جاملة زي [مثل] دايما [دائمًا]

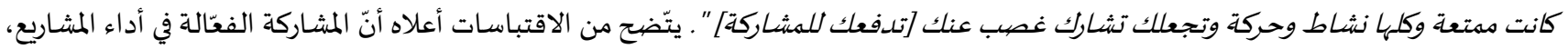
في بيئة تعليمياة-تعلمية تتميز بالمرونة والد افعية والمشاركة النشطة، كان أحد أهم أسباب استمتاع الطالبات في دراسة الرياضيات بطريقة التعلم القائم

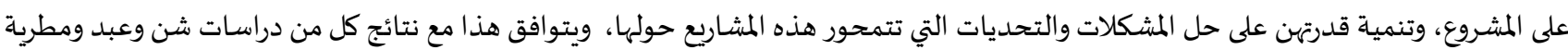

( T. Chin, 2014) كما يمكن القول بأنّ العمل على المشاريع، خلق بيئة تعليمية أكثر إثارة للاهتمام، وممتعة، ومفيدة للطالبات البات، وتسمح لهن ببناء المعرفة الرياضية

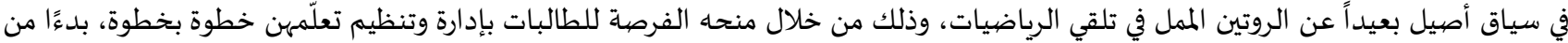

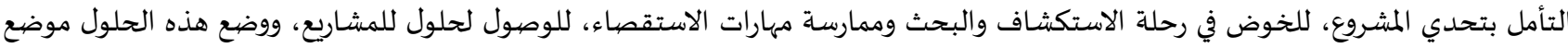


التطبيق، والخروج بمنتجات أصيلة، وهذا يتطلب منهن تفحص المعلومات المتوافرة في المصادر المتعددة بدقة، والنظر في أوجه الشبه والاختلاف في هذه المعلومات، وإدراك العلاقات بينها، والتوصل لعلاقات جديدة، وصياغة أفكار رياضية عامة بناءً على حالات خاصة،، وهو ما يمثل جوهر التعميم

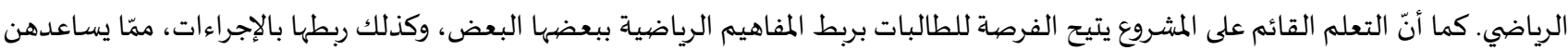
على بناء مفاهيم الوحدة من خلال التعميمات التي توصلن إلها أثناء أداء المشاريع. وبهذا تتوافق هذه النتائج مع ما توصلت إليه دراسة هزهوزي (

ولا شكّ أنّ ما قامت الطالبات بممارسته في تفحص المشاريع من جوانب متعددة، وجمع المعلومات من مصادر متاحة وإدارتها، مثل فصل

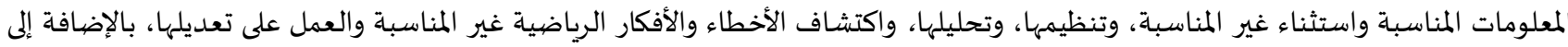

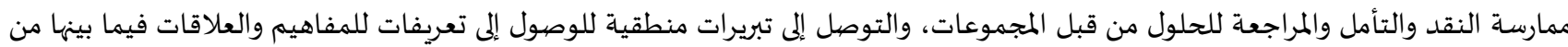

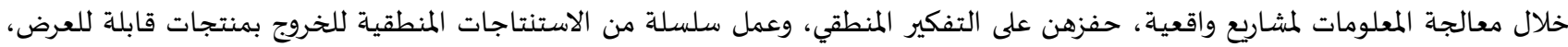

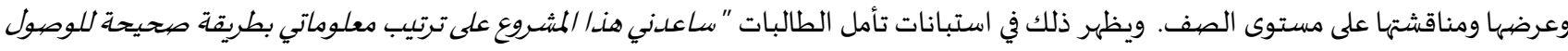
إلى الحل" ، وأشارت أخرى" واجهت صعوبة في تجميع المعلومات من مصادر مختلفة وبعدين (ثمّر) كتابتها بطريقة منظمة" . ويتوافق هذا مع نتائج دراستي

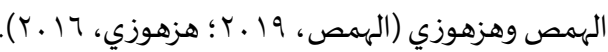

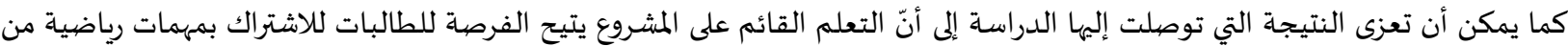
الصعب حلها من خلال الحفظ عن ظهر قلب للخوارزميات والإجراءات، بل تتطلب تعلما عميقا وغنيا لما وراء هذه الإجراءات، وذلك ما حدث من خله خلال تسهيل المعلمة للمناقشّة أثناء أداء المشاريع والتي تعدّ أداة مفيدة لمساعدة الطالبات على الفهم وعمل شبكة من الروابط بين الأفكار والمفاهيم والإجراءات الرياضية، والتي تشكل الإنعكاسية جانبا منها. وعلى الرغم من الصعوبة التي يواجهها الطلبة بشكل عام بالقدرة الانعكاسية، فإنّ تنفيذ إنداء

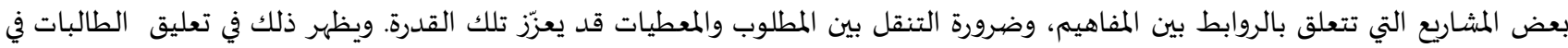

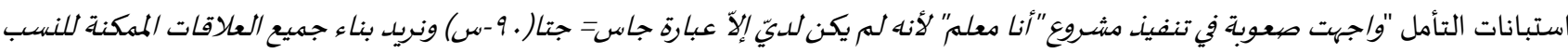

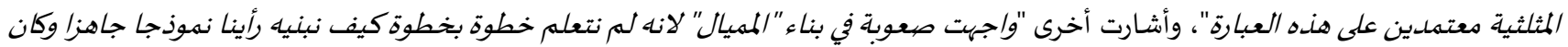

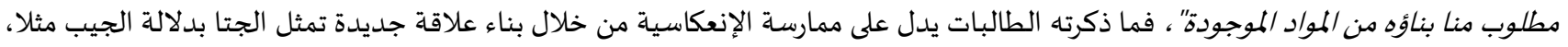

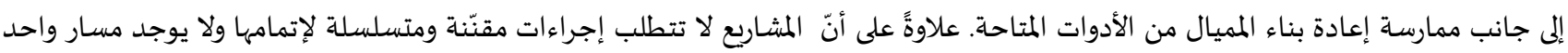

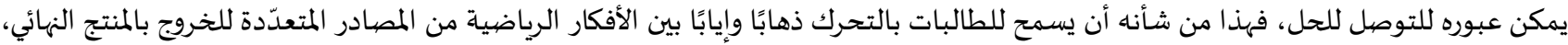

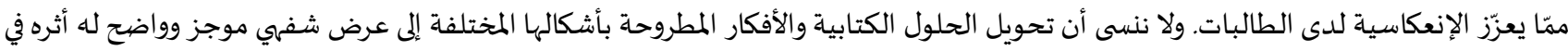
حرص الطالبات على تنظيم المعرفة وربطها بطريقة منظمة والانتقال بين التمثيلات المختلفة للفكرة الرياضية، وهذا بدوره يحفّز الإنعكاسية كما أشار

فلاندرز (Flanders, 2015).

ويمكن إرجاع الأداء المميز لطالبات المجموعة التجريبية إلى ما يتميز به التعلم القائم على المشروع من مرونة في المعرفة والنتاجات التي تتوصل إليها

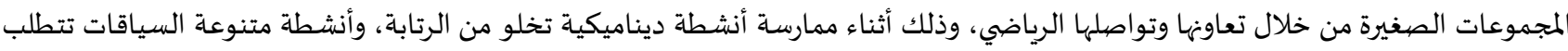

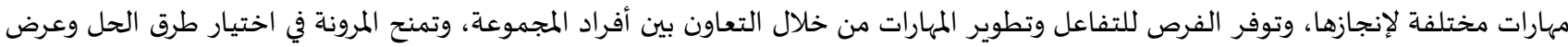

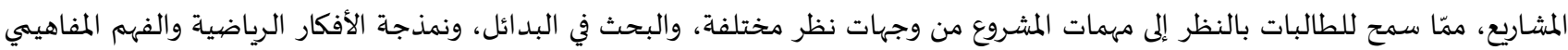

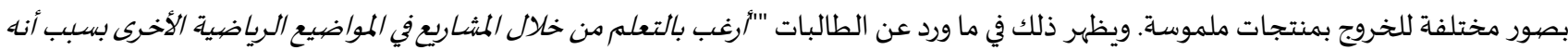

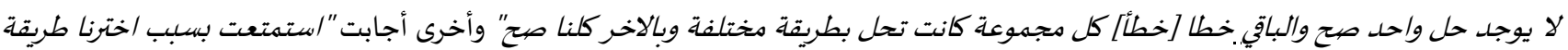

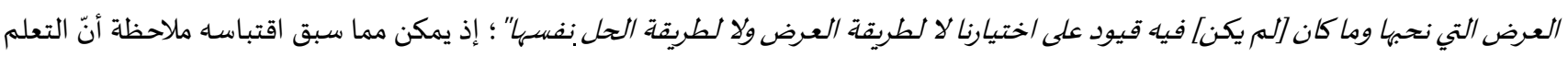
القائم على المشروع ينمّي المرونة لدى الطالبات. وتتفق هذه الدراسة في ذلك مع نتائج دراسـة أومّا وإنعام وعزمي (Ummah, In’am \& Azmi, 2019).

الإستنتاجات والتوصيات:

إنّ تنمية القدرة الرياضية لا يحدث فجأة، ولا يمكن أن يكون عملية تلقائية، بل يحتاج إلى عمليات هادفة تتّم في بيئات تعلمية - تعليمية نشطة.

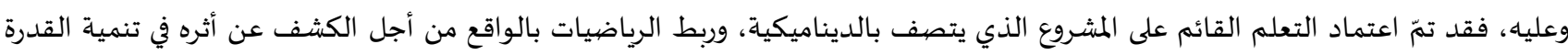
الرياضية بمكوناتها: التعميم، والمنطق، والانعكاسية، والمرونة حسب ما جاء عن كروتيسكي. وفي ظل نتائج الدراسـة، فقد خلصت إلى استنتاج رئيس وهو

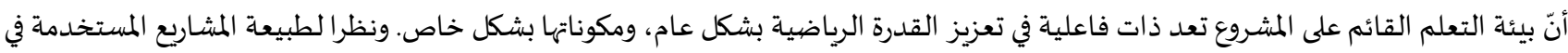

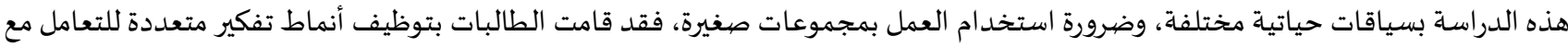
هذه المشاريع ممّا أدى إلى تفوق التعلم القائم على المشروع على الطريقة التقليدية في تنمية القدرة الرياضية لدى الطالبات. علاوة على ما سبق، فقد كان 
للتعلم القائم على المشروع أثرا ملموسا وايجابيا في الدافعية نحو التعلم والمشاركة الصفية، إضافة إلى منح فرص التأمل والتقييم الذاتي من قبل الطالبات كجزء أساسي من إجراءات التعلم القائم على المشروع. وفي ضوء ما سبق، يمكن التوصياة بالآتي:

ا. توظيف التعلم القائم على المشروع في تدريس الرياضيات من قبل المعلمين، لما أظهره من أثر إيجابي في تحسين القدرة الرياضياة.

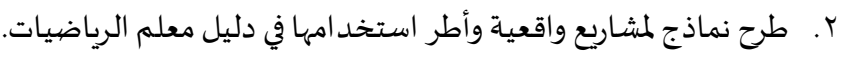

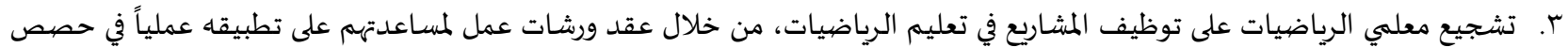
الرياضيات.

ع. إجراء المزيد من الدراسات التي تتناول التعلم القائم على المشروع في الرياضيات، بحيث تشمل موضوعات رياضية مختلفة، ومراحل تعليمية

$$
\text { أخرى، ومزيد من القدرات الرياضياة. }
$$

$$
\text { أولاً: المراجع العربية: }
$$

ا. عبد، إيمان. (Y ا . Y). "أثر استخدام استراتيجية التعلم المستند إلى طريقة المشروع في تنمية حل المشكلات لدى طلبة كلية العلوم التربوية والآداب

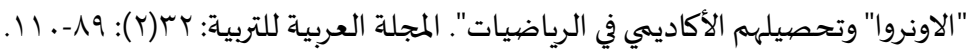

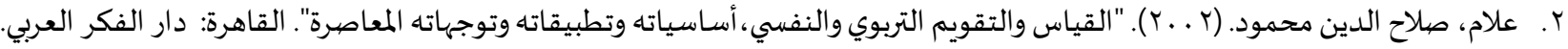

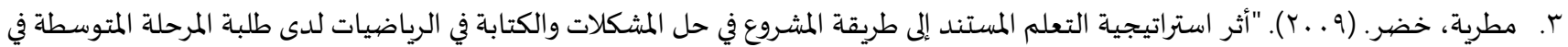
السعودية". أطروحة دكتوراة غير منشورة. جامعة عمان العربية. عمان. الأردن.

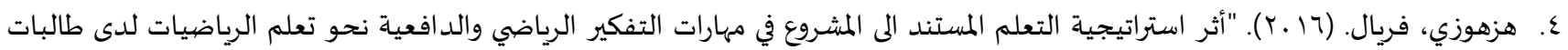
الصف السابع الأساسي في محافظة جنين". رسالة ماجستير غير منشورة. جامعة النجاح الوطنية. نابلس: فلسطين.

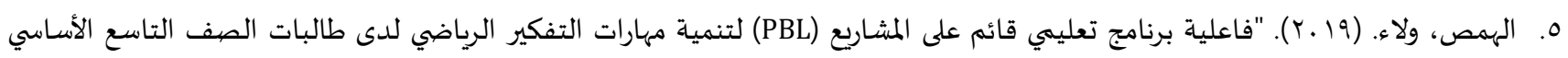
بغزة." رسالة ماجستير غير منشورة. الجامعة الإسلامية. غزة: فلسطين.

ثانياً: المراجع الأجنبية:

[1] Ababneh, E., Al-Tweissi, A., \& Abulibdeh, K. (2016). "TIMSS and PISA impact - the case of Jordan". Research Papers in Education, 31(5): 542-555. https://doi.org/10.1080/02671522.2016.1225350.

[2] Allen, M. J., \& Yen, W. M. (1979). “Introduction to measurement theory”. Monterey, California: Brooks/Cole Pub. Co.

[3] Bell, S. (2010). "Project-based learning for the 21st century: Skills for the future". The Clearing House: A Journal of Educational Strategies, Issues and Ideas, 83(2): 39-43.

[4] Bender, W. N. (2012). "Project-based learning: Differentiating instruction for the 21st century". Thousand Oaks, CA: Corwin Press.

[5] Buck Institute for Education. (2018). "What is Project Based Learning?" Retrieved September 12, 2018, from https://www.bie.org/about/what PBL.

[6] Cervantes, B., Hemmer, L., \& Kouzekanani, K. (2015). "The impact of project-based learning on minority student achievement: Implications for school redesign". NCPEA Education Leadership Review of Doctoral Research, 2(2): 1-50.

[7] Chin, W. (2014). "The effects of Project-Based learning in high school geometry". Unpublished Doctoral Dissertation, University of Manoa, Hawai.

[8] Dindyal, J. (2007). "High school students' use of patterns and generalizations (pp. 236-245)". the 30th Annual Conferences of the Mathematics Education Research Group of Australasia.

[9] Doppelt, Y. (2003). "Implementation and assessment of project-based learning in a flexible environment". International Journal of Technology and Design Education, 13: 255-272.

[10] Dougherty, B., Bryant, D. P., Bryant, B. R., Darrough, R. L., \& Pfannenstiel, K. H. (2015). "Developing concepts and generalizations to build algebraic thinking: The reversibility, flexibility, and generalization approach". Intervention in School and Clinic, 50, 273-281. doi:10.1177/1053451214560892. 
[11] Dündar, S., Temel, H., \& Gündüz, N. (2016). "Development of a mathematical ability test: a validity and reliability study". International Journal of Mathematical Education in Science and Technology, 47(7): 1061-1075. https://doi.org/10.1080/0020739x.2016.1153734.

[12] Essien, A. M. (2018). "The effects of project-based learning on students' English language ability (pp. 438-443)". The 2018 International Academic Research Conference, Vienna.

[13] Flanders, S. (2015) "Investigating flexibility, reversibility, and multiple representations in a calculus environment". Unpublished Doctoral Dissertation, University of Pittsburgh.

[14] Fleming, D. S. (2000). “A Teacher's Guide to Project-Based Learning”. Washington: ERIC.

[15] Gerhana, M., Mardiyana, M., \&Pramudya, I. (2017)." The Effectiveness of Project Based Learning in Trigonometry". International Conference on Mathematics and Science Education (ICMScE), Conf. Series895. doi :10.1088/17426596/895/1/012027.

[16] Jacques, L. (2017). “What does Project-based Learning (PBL) Look like in the Mathematics Classroom?”. American Journal of Educational Research, 5(4): 428-433.

[17] Jones, B. (2019). "Good practice: Scaffolded, Collaborative Project-based Learning". Journal of the European Honors Council, 3(1): 11-27. https://doi.org/10.31378/jehc.85.

[18] Knoll, M. (2014). "Project method. In C.D. Phillips (Ed), Encyclopedia of educational theory and philosophy (PP. 665669)". London: SAGE.

[19] Koparan, T., \& Guven, B. (2014). "The Effect on the 8th grade Students' Attitude towards Statistics of Project Based Learning". European Journal of Educational Research. 3(2): 73-85. https://doi.org/10.12973/eu-jer.3.2.73.

[20] Krutetskii, V. (1976). "The psychology of mathematical abilities in school- children". Chicago, IL: The University of Chicago Press.

[21] Lee, J. (2018). “An Inquiry-based Approach: project-based learning. NCTM. Rigor, Relevance, and Relationships: Making Mathematics Come Alive with project-based learning". Retrieved August 15, 2018, from https://www.nctm.org/Store/Products/Rigor,-Relevance,-and-Relationships--Making-Mathematics-Come-Alive-with-Project-BasedLearning/.

[22] Maharani, H.R. (2014). "Creative Thinking in Mathematics: Are We Able to Solve Mahematical Problems in a Variety of Way?". International Conference on Mathematics, Science, and Education (ICMSE 2014). Semarang.

[23] Mahmudi, A. (2011). "Project-based learning. Material of Course on Joyful Learning in Mathematics for Primary School Mathematics Teacher". Quality Improvement of Teachers and Educational Personnel in Mathematics, tanggal 2-22 Juli 2011. Yogyakarta.

[24] Mihajlović, A., Egerić, M., \& Dejić, M. (2008). "Mathematical Abilities: Identification and Development". Retrieved September 1 , 2018, from https://www.researchgate.net/publication/290430034 MATHEMATICAL ABILITIES IDENTIFICATION AND DEVELOPMENT

[25] Peterson, B. W. (2012). "Uncovering the progressive past: The origins of project based learning". Unboxed: A Journal of Adult Learning in Schools, 8. Retrieved January 22, 2019, from http://gse.hightechhigh.org/unboxed/issue8/uncovering the progressive past/.

[26] Ramful, A., \& Olive, J. (2008). "Reversibility of thought: An instance in multiplicative tasks". Journal of Mathematical Behavior, 27(2): 138-151. https://doi.org/10.1016/j.jmathb.2008.07.005.

[27] Remijan, K. (2017). "Project-Based Learning and Design-Focused Projects to Motivate Secondary Mathematics Students". Interdisciplinary Journal of Problem-Based Learning, 11(1). Retrieved August 14, 2018, from http://docs.lib.purdue.edu/ijpbl/vol11/iss1/1/.

[28] Stubbs, S. (2016). "Project-Based Learning in Mathematics: A Middle School Curriculum Unit”. Unpublished Master's Thesis, Brock University, Ontario.

[29] Szabo, A. (2017). "Mathematical abilities and mathematical memory during problem solving and some aspects of mathematics education for gifted pupils”. Doctoral Dissertation, Stockholm University, Stockholm.

[30] Teachey, A.L. (2003). "Investigation in conceptual understanding of polynomial function and the impact of mathematical beliefs systems on achievement in an accelerated summer program for gifted students". Doctoral Dissertation. University of North Carolina, USA.

[31] Thomas, J.W. (2000). "A review of research on project-based learning”. San Rafael, CA: Autodesk Foundation.

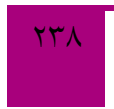


[32] Ummah, S.K., In'am, A., Azmi, R.D. (2019). “Creating Manipulatives: Improving Students' Creativity Through Project-Based Learning". Journal on Mathematics Education, 10(1): 93-102. https://doi.org/10.22342/jme.10.1.5093.93-102.

[33] Usiskin, Z. (1999). "The mathematically promising and the mathematically gifted". In L. J. Sheffield (Ed.), Developing mathematically promising students (pp. 57-69). Reston, VA: National Council of Teachers of Mathematics.

[34] Uyangor, S. (2012). "The effects of project-based learning on teaching of polygon and plane geometry unit". New Educational Review, 29(3): 212-223.

[35] Vilkomir, T., \& O’Donoghue, J. (2009). “Using components of mathematical ability for initial development and identification of mathematically promising students". International Journal of Mathematical Education in Science and Technology, 40(2): 183-199. https://doi.org/10.1080/00207390802276200.

[36] Yoo, J., \& Maher, D. (2017). “Project-based Learning In The Primary School Classroom”. Retrieved September 12, 2018, from https://www.researchgate.net/publication/314281465 Project based learning in the primary school classroom. 
المجلة الدولية للدراسـات التربوية والنفسية

International Journal of Educational \& Psychological Studies (EPS)

Journal Homepage: https://www.refaad.com/views/EPSR/Home.aspx

www.refaad.com

ISSN: 2520-4149 (Online) 2520-4130 (Print)

\title{
The effect of using project-based learning (PBL) on mathematical ability among 9th grade female students in Jordan
}

\author{
Alaa Ahmed AL-zatari \\ PhD student in mathematics curricula and teaching methods, Curriculum and Instruction Department, College of \\ Education, Yarmouk University, Jordan \\ Alaa2014403122@gmail.com
}

Amal Abdallah Khasawneh

Professor in Mathematics Curricula and Teaching Methods, College of Education, Yarmouk University, Jordan amal.khasawneh@yu.edu.jo

Received : 5/4/2020 Revised : 18/4/2020 Accepted : 25/4/2020 DOI : https://doi.org/10.31559/EPS2021.9.1.14

Abstract: This study aimed to investigate the effect of Project-Based Learning (PBL) on the mathematical ability of the ninth-grade female students. The study used a quasi-experimental approach. The study sample consisted of (47) female students enrolled in one of public school in Jerash for the academic year 2018/2019, they were distributed into two groups, the experimental group $(\mathrm{n}=26)$ which was taught mathematics through project-based learning $(\mathrm{PBL})$, and the control group $(\mathrm{n}=21)$, which was taught through the traditional method. To achieve the objectives of the study, four projects were used to teach the unit of trigonometric ratios, and a mathematical ability test was applied before and after the experiment. The findings revealed that the experimental group scored higher than the control group on the mathematical ability test as a whole and on each of its components (generalization, Logic, reversibility, flexibility), which means that there were statistically significant differences between the means of the experimental and the control groups on the mathematical ability test and on its components due to the teaching method, in favor of the experimental group. In regard of the results, it was recommended that the teachers of mathematics could adopt the project-based learning approach in teaching mathematics and more studies dealing with projectbased learning in mathematics should be conducted in different educational levels and different mathematics subjects.

Keywords: Mathematics Education; Generalization; logic; Reversibility; Flexibility; Krutetskii model.

\section{References:}

[1] 'bd, Eyman. (2012). "Athr Astkhdam Astratyjyh Alt'lm Almstnd Ela Tryqh Almshrw' Fy Tnmyh Hl Almshklat Lda Tlbt Klyh Al'lwm Altrbwyh Waladab "Alawnrwa" Wthsylhm Alakadymy Fy Alryadyat". Almjlh Al'rbyh Lltrbyh: 32(2): 89-110.

[2] 'lam, Slah Aldyn Mhmwd. (2002). "Alqyas Waltqwym Altrbwy Walnfsy,Asasyath Wttbyqath Wtwjhath Alm'asrh". Alqahrh: Dar Alfkr Al'erby.

[3] Alhms, Wla'. (2019). "Fa'lyt Brnamj T'lymy Qa'm 'la Almshary' (Pbl) Ltnmyh Mharat Altfkyr Alryady Lda Talbat Alsf Altas' Alasasy Bghzh." Rsalt Majstyr Ghyr Mnshwrh. Aljam'h Aleslamyh. Ghzh: Flstyn.

[4] Hzhwzy, Fryal. (2016). "Athr Astratyjyh Alt'lm Almstnd Ala Almshrw' Fy Mharat Altfkyr Alryady Waldaf'yh Nhw T'lm Alryadyat Lda Talbat Alsf Alsab' Alasasy Fy Mhafzt Jnyn". Rsalt Majstyr Ghyr Mnshwrh. Jam't Alnjah Alwtnyh. Nabls: Flstyn.

[5] Mtryh, Khdr. (2009). "Athr Astratyjyh Alt'Im Almstnd Ela Tryqt Almshrw' Fy Hl Almshklat Walktabh Fy Alryadyat Lda Tlbt Almrhlh Almtwsth Fy Als'wdyh". Atrwht Dktwrah Ghyr Mnshwrh. Jam't 'man Al'rbyh. 'man. Alardn.

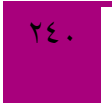

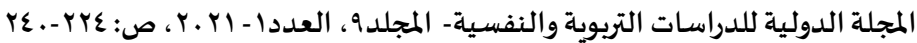

